\title{
A CFD study of biomass pyrolysis in a downer reactor equipped with a novel gas-solid separator: part II Thermochemical performance and products
}

\author{
Xi Yu ${ }^{1}$, Mohamed Hassan ${ }^{1}$, Raffaella Ocone ${ }^{2}$, Yassir Makkawi ${ }^{1, *}$
}

1 European Bioenergy Research Institute (EBRI), School of Engineering and Applied Science, Aston University, Birmingham B4 7ET, UK

2 Chemical Engineering, Heriot-Watt University, Edinburgh EH14 4AS, UK

\section{Highlight}

- A CFD model is used to simulate biomass fast pyrolysis in a downer reactor.

- An Eulerian-Eulerian approach with a single global pyrolysis reaction is used.

- A novel gas-solid separator was used to control the gas residence time.

- Predicted pyrolysis yield is in good agreement with reported literature data.

\section{Abstract}

A Eulerian-Eulerian CFD model was used to investigate the fast pyrolysis of biomass in a downer reactor equipped with a novel gas-solid separation mechanism. The highly endothermic pyrolysis reaction was assumed to be entirely driven by an inert solid heat carrier (sand). A one-step global pyrolysis reaction, along with the equations describing the biomass drying and heat transfer, was implemented in the hydrodynamic model presented in part I of this study (Fuel Processing Technology, V126, 366-382). The predictions of the gas-solid separation efficiency, temperature distribution, residence time and the pyrolysis product yield are presented and discussed. For the operating conditions considered, the devolatilisation efficiency was found to be above $60 \%$ and the yield composition in mass fraction was $56.85 \%$ bio-oil, $37.87 \%$ bio-char and $5.28 \%$ non-condensable gas (NCG). This has been found to agree reasonably well with recent relevant published experimental data. The novel gas-solid separation mechanism allowed achieving greater than $99.9 \%$ separation efficiency and $<2 \mathrm{~s}$ pyrolysis gas residence time. The model has been found to be robust and fast in terms of computational time, thus has the great 
potential to aid in future design and optimisation of the biomass fast pyrolysis process.

Key words: Biomass pyrolysis, CFD modelling, fast pyrolysis, downer reactor

\section{Introduction}

Biomass pyrolysis has emerged as a very promising renewable energy technology for the production of bio-oil. This is a robust thermo-chemical process that takes place in a controlled environment (reactor) to convert low density organic materials into vapour, liquid and solid (bio-char) at a high temperature within the range of $400{ }^{\circ} \mathrm{C}$ to $550{ }^{\circ} \mathrm{C}$ and in the absence of oxygen [1-3]. The vapour is quickly condensed in a quenching system to produce a liquid (bio-oil) and a permanent noncondensable gas (NCG) phase, mainly consisting of $\mathrm{CO}, \mathrm{CO}_{2}$ and small fractions of $\mathrm{H}_{2}$ and $\mathrm{CH}_{4}$ [4]. Previous studies have shown that the biomass pyrolysis process requires careful control of the reactor temperature and residence times in order to increase the bio-oil yield. The pyrolysis vapour needs to be removed quickly from the reactor hot zone to avoid secondary cracking reactions. It is also recommended to limit the time of contact between the pyrolysis vapour and the bio-char to minimize catalytic cracking [4]. The process is usually classified as fast pyrolysis If the heating rate is rapid $\left(1000^{\circ} \mathrm{C} / \mathrm{s}-10,000^{\circ} \mathrm{C} / \mathrm{s}\right)[5]$ and the gas residence time is less than $2 \mathrm{~s}$ $[2,6]$. Fast pyrolysis of biomass has the advantage of maximising the yield of bio-oil, typically produces 50 to $70 \%$ bio-oil, 0 to $30 \%$ bio-char, and 15 to $20 \%$ NCG [1].

In the first part of this study, Yu et al [7] theoretically studied a downer reactor equipped with a novel solid gas separation mechanism. The study presented a valid computational fluid dynamic (CFD) model to predict the reactor multiphase flow features and provide the platform for further development to predict biomass pyrolysis behaviour and products. Compared to the other available biomass pyrolysis technologies, the proposed reactor, arranged in a dual fluidized bed system, was found to be a viable option to ensure narrow residence time distribution of the gas phases, as well as quick and efficient separation of the gas from the solid phase. In addition, such arrangement is believed to guarantee sustainable operation without the reliance on external heating through the combustion of the produced bio-char [8]. 
CFD modelling of biomass fast pyrolysis is a challenging task due the complex simultaneous interactions between the various phases while the biomass particles undergo rapid thermo-chemical conversion to gases and solid residues (char). Nevertheless, CFD modelling for thermochemical conversion processes is fast developing nowadays due to the availability of high performance computers and the improved accuracy and reliability of the developed models. One of the pioneering works on modelling biomass pyrolysis was reported by Miller and Bellan [9], where mathematical solution of multi-step kinetics coupled with simple porous particle model proved to provide reliable predictions compared to thermogravometry experiments.

For the simulation of biomass pyrolysis or gasification during free fall or suspension, such as in a downer or fluidized bed reactor, the overall process is commonly simulated by coupling the solution of the flow hydrodynamics with the thermochemical changes associated with the biomass decomposition. A brief summary of the recent reported CFD studies of biomass pyrolysis is given in Table 1 . These models are based on Eulerian-Lagrangian or Eulerian-Eulerian modelling approaches. The latter is considerably superior in terms of computational time, especially when handling real scale reactive system in three dimensional coordinates. As far as the authors' knowledge, no modelling attempt has been reported in the literature for fast pyrolysis of biomass in a downer reactor, whilst there are few studies on bubbling and circulating fluidized bed reactors as discussed here. Papadikis et al $[10,14,17]$ investigate the heat and mass transfer and the particle shrinkage impact during the pyrolysis process in a fluidized bed reactor using an Eulerian-Lagrangian approach. The details at the single particle level were revealed by tracing a single cellulosic particle in the fluidized bed. Xue et al [18, 20, 21] developed an Eulerian-Eulerian CFD model with multi-component, multi-stages kinetics model to simulate biomass fast pyrolysis in a lab-scale fluidized bed. The study proposed various model improvements by taking into account detailed pyrolysis kinetics with a multi-component, particle density variation, and particle size distribution. Boateng and Mtui [22] developed an Eulerian-Eulerian model for biomass fast pyrolysis in a bubbling fluidized bed using one-step global pyrolysis reaction. The composition of the biomass feed was treated as fixed in carbon, volatile 
matter, moisture content and ash content obtained from experimental proximate analysis. The study concluded that such a modelling approach is especially suitable for the design of fast pyrolysis reactors and their optimization to meet economic scales required for distributed or satellite units. Ashcraft et al [23] modelled a gassolid vortex reactor for assessing the potential of the centrifugal fluidization reactor technology and exploring its process intensification abilities using Eulerian-Eulerian approach with multi-component, multi-stages kinetics model. Xiong et al [24] investigated the effects of operating conditions on biomass fast pyrolysis in bubbling fluidized bed using Eulerian-Eulerian approach with Shafizadeh-Chin decomposition model [9], the prediction was found to be in good agreement with experimental data. Most recently, Mellin et al [26] developed and implemented a more detailed numerical reaction network for the simulation of biomass pyrolysis in a bubbling fluidized bed reactor. The model was solved using ANSYS-FLUENT CFD commercial code. The multiphase flow hydrodynamics and the complex scheme of reactions included decomposition of each biomass subcomponent in primary and secondary pyrolysis reactions. Due to the complexity and large number of the reactions considered, the reported computational time was considerable high. The predicted pyrolysis products were found to satisfactory match the experimental data, apart from the water content being under-predicted.

In this second part of the study, the CFD hydrodynamic model developed in part I [7] has been extended to include equations describing the heat transfer and thermochemical reactions taking place during fast pyrolysis of biomass. The main objectives of this paper are:

I. To present a CFD model capable of predicting the product composition (gas, oil, char) during fast pyrolysis of biomass in a downer reactor, where the conversion reaction is entirely driven by a circulating inert solid particulate phase.

II. To evaluate the separation of the pyrolysis product gas from the multi-solid flow mixture (heat carrier and bio-char) using a novel separator developed by researchers at the Institute for Chemicals and Fuels from Alternative Resources (ICFAR) in Canada [30].

III. To study the residence time of the various phases and the evolution of heat transfer and temperature distribution inside the reactor.

IV. To provide a robust tool for the development, optimization and scale up analysis 
of downer pyrolysis reactors in general and that is equipped with the proposed novel separator in particular.

The CFD transient model was solved in three-dimensional coordinates using the latest ANSYS-FLUENT CFD code (Ver 15.0). The model formulation is presented with focus on the new equations added to the original hydrodynamic model developed in the first part of this study in order to take into consideration the thermos-chemical reaction associated with the biomass conversion. The pyrolysis reaction was implemented in the CFD model using an in-house developed user defined function (UDF) based on one-step global reaction scheme for biomass pyrolysis, as detailed in Section 3.3.2.

\section{Computational domain and operating conditions}

Fig. 1 shows the overall biomass pyrolysis concept, and the computational domain indicated by the dashed line around the pyrolysis reactor only. The flow in the pyrolysis reactor includes two different solid materials (inert heat carrier and biomass) and a gas phase (carrier nitrogen and product hydrocarbons). Details on the meshing method, number of cells and the dimensions of the computational domain can be found in part I of this study [7]. This is described briefly here as a column of $6.9 \mathrm{~cm}$ diameter and $133.5 \mathrm{~cm}$ height connected at the lower part to a solid receiving tank. The reactor is equipped with a novel gas-solid separation mechanism developed by researchers at the ICFAR in Canada [30]. This consisted of (i) a conical solid deflector of internal angles of 60 degree and a height of $5.5 \mathrm{~cm}$ located $98.6 \mathrm{~cm}$ below the downer reactor top, and (ii) a gas discharge pipe located at the centre of the cone base. Further details of the deflector and its use in solid-gas separation in downer reactors can be found in [7, 30]. The Biomass feedstock considered in this study is switch grass of spherical shape of $200 \mu \mathrm{m}$ diameter fed into the top of the reactor at the temperature of $298 \mathrm{~K}$ and flow rate of $5 \mathrm{~g} / \mathrm{s}$. Carrier gas (nitrogen) is fed at a superficial velocity of $0.05 \mathrm{~m} / \mathrm{s}$ and a temperature of $298 \mathrm{~K}$. The gas stream, along with any entrained particles, exits the system through the gas outlet pipe. 
The highly endothermic biomass pyrolysis process is assumed to be driven by hot circulating inert particulate phase (sand) entering the top of the reactor from a connected combustor at a high temperature of $700{ }^{\circ} \mathrm{C}$. In order to estimate the sand flow rate that will satisfy the required thermal input, $Q_{i n}$, for pyrolysis, a simple energy balance was used as follows [31]:

$Q_{\text {in }}=\sum m \Delta H_{f, 298, f e e d}^{\circ}+\sum m \Delta H_{\text {feed }}(T)-\sum n \Delta H_{f, 298, f e e d}^{\circ}-\sum n \Delta H_{\text {feed }}(T)$

where $\Delta H_{f, 298, f e e d}^{\circ}$ and $\Delta H_{f, 298, p r o d}^{\circ}$ are the heats of formation of feed and product materials at temperature $298 \mathrm{~K}$ per kg material; $H_{\text {feed }}(T)$ and $H_{\text {prod }}(T)$ are the heat of formation at temperature $T$ (pyrolysis temperature) and are given by the following formula:

$H(T)=\Delta H_{f, 298}^{0}+\int_{298}^{T} C_{p} d T$

The heat of formation of biomass, bio-oil and char were calculated using the following equation [32],

$\Delta H_{f, 298}^{0}=H H V-(0.327 C+1.417 H+92.57 S+0.158 M)$

where HHV represent the higher heating value $(\mathrm{MJ} / \mathrm{kg})$. C, $H, S$ and $M$ represent the percentage mass fraction of carbon, hydrogen, sulphur and moisture contents in the fuel respectively. The HHV (MJ/kg) was calculated based on the unified correlation for solid and liquid fuels proposed by Channiwala and Parikh [33] as follows:

$H H V=0.3491 C+1.1783 H+0.1005 S-0.1034 O-0.0151 N-0.0211 A$

where $O, N$ and $A$ represent percentage mass fraction of oxygen, nitrogen and ash on dry basis respectively. The composition of the various fuels used in the Eqs. 3 and 4 were obtained from the experimental data on switch grass pyrolysis reported by Boateng and Mtui [22]. For a biomass flow rate of $5 \mathrm{~g} / \mathrm{s}$ and an ideal case of product yield of $60 \%$ bio-oil, $30 \%$ bio-char and 10\% NCG the above equation gives an estimate thermal input of $9.3 \mathrm{~kW}$. For a solid inlet temperature of $700{ }^{\circ} \mathrm{C}$ and an average reactor temperature of $500{ }^{\circ} \mathrm{C}$, this roughly corresponds to a sand flow rate of $80 \mathrm{~g} / \mathrm{s}$, which is 16 times the biomass feed rate. Further details on the reactor operating conditions and the physical properties of the material used in the model are given in Table 2. 


\section{Modelling approach}

The following sections present the mathematical formulation used to describe (i) the mass, momentum and granular energy equations (ii) the heat transfer between the solid and gas phases in addition to endothermic heat of pyrolysis reaction, and (ii) the mass transfer of species resulting from biomass drying and thermal degradation (devolatilization). The devolatilization rate equation and kinetics have been implemented in the CFD model using in-house developed UDF in $\mathrm{C}++$ language, as given in Appendix A. The details of the original hydrodynamic model (unreactive cold flow) can be found in part I of this study [7].

\subsection{Continuity, momentum and granular temperature}

The multi-solid phase Eulerian-Eluerian model developed in the first part of this study [7] has been modified to include the overall mass exchange between the gas phase and the biomass. The modified continuity, momentum and granular temperature equations are as follows:

Continuity equations:

$$
\begin{aligned}
& \frac{\partial\left(\alpha_{g} \rho_{g}\right)}{\partial t}+\nabla\left(\alpha_{g} \rho_{g} \vec{u}_{g}\right)=R_{g} \\
& \frac{\partial\left(\alpha_{s_{i}} \rho_{s_{i}}\right)}{\partial t}+\nabla\left(\alpha_{s_{i}} \rho_{s_{i}} \vec{u}_{s_{i}}\right)=R_{S_{i}} \\
& \sum_{i=1}^{2} \alpha_{s_{i}}+\alpha_{g}=1
\end{aligned}
$$

where $\alpha$ is the volume fraction, $\rho$ is the density. $\vec{u}$ is the velocity vector, $R$ is the interphase mass transfer due to surface chemistry at interface (pyrolysis) or evaporation. The subscript $g, s_{1}$ and $s_{2}$ stand for gas, sand and biomass phases respectively. Note that, $R_{s_{1}}=0$ for the inert solid (sand).

Momentum equations:

$$
\begin{aligned}
\frac{\partial\left(\alpha_{g} \rho_{g} \vec{u}_{g}\right)}{\partial t}+\nabla\left(\alpha_{g} \rho_{g} \vec{u}_{g} \vec{u}_{g}\right)=-\alpha_{g} \nabla P+\nabla \overline{\bar{\tau}}_{g} & -\sum_{i=1}^{2} \beta_{g s_{i}}\left(\vec{u}_{g}-\vec{u}_{s_{i}}\right) \\
& +\alpha_{g} \rho_{g} \vec{g}+\vec{R}_{s_{2} g}+\dot{m}_{s_{2} g} \vec{u}_{s_{2} g}
\end{aligned}
$$




$$
\begin{aligned}
\frac{\partial\left(\alpha_{s_{1}} \rho_{s_{1}} \vec{u}_{s_{1}}\right)}{\partial t}+\nabla\left(\alpha_{s_{1}} \rho_{s_{1}} \vec{u}_{s_{1}} \vec{u}_{s_{1}}\right)= & -\alpha_{s_{1}} \nabla P-\nabla P_{s_{1}}+\nabla \overline{\bar{\tau}}_{s_{1}}+\beta_{g s_{1}}\left(\vec{u}_{g}-\vec{u}_{s_{1}}\right) \\
& +\beta_{s_{1} s_{2}}\left(\vec{u}_{s_{2}}-\vec{u}_{s_{1}}\right)+\alpha_{s_{1}} \rho_{s_{1}} \vec{g} \\
\frac{\partial\left(\alpha_{s_{2}} \rho_{s_{2}} \vec{u}_{s_{2}}\right)}{\partial t}+\nabla\left(\alpha_{s_{2}} \rho_{s_{2}} \vec{u}_{s_{2}} \vec{u}_{s_{2}}\right)= & -\alpha_{s_{2}} \nabla P-\nabla P_{s_{2}}+\nabla \overline{\bar{\tau}}_{s_{2}}+\beta_{g s_{2}}\left(\vec{u}_{g}-\vec{u}_{s_{2}}\right) \\
+ & \beta_{s_{2} s_{1}}\left(\vec{u}_{s_{1}}-\vec{u}_{s_{2}}\right)+\alpha_{s_{2}} \rho_{s_{2}} \vec{g}+\vec{R}_{g s_{2}}-\dot{m}_{s_{2} g} \vec{u}_{s_{2} g}
\end{aligned}
$$

where $\beta_{g s}$ and $\beta_{s s}$ are the gas-solid and solid-solid momentum exchange coefficients, respectively, $\vec{g}$ is the gravity constant, $\overline{\bar{\tau}}$ is the solid shear stress tensor, $\vec{R}=R \times \vec{u}$ is the interphase momentum transfer due to the pyrolysis reaction, and $\dot{m} \vec{u}$ is the interphase momentum transfer due to evaporation. Note that $\vec{R}$ and $\dot{m} \vec{u}$ are not included in Eq. 9, due to the inert nature of the sand particles.

Granular temperature equations:

$$
\begin{aligned}
\frac{3}{2}\left[\frac{\partial\left(\alpha_{s_{i}} \rho_{s} \Theta_{s_{i}}\right)}{\partial t}\right. & \left.+\nabla\left(\alpha_{s_{i}} \rho_{s} \Theta_{s_{i}}\right) \vec{u}_{s_{i}}\right] \\
= & \left(-P_{s_{i}} \overline{\bar{I}}+\overline{\bar{\tau}}_{s_{i}}\right): \nabla \vec{u}_{s_{i}}+\nabla\left(\kappa_{\Theta_{s_{i}}} \nabla \Theta_{s_{i}}\right)-\gamma_{\Theta_{s_{i}}}+\sum_{k=1}^{2} \phi_{k s_{i}}
\end{aligned}
$$

where $\Theta_{S}$ is granular temperature of solid phase, $\kappa_{\theta_{S}}$ is diffusion coefficient of granular energy, and $\phi_{k s}$ is energy exchange between phase $k$ and solid phase.

\subsection{Gas species conservation and heat transfer}

The conservation equations of species transport in the gas phase are given by:

$$
\begin{aligned}
& \frac{\partial\left(\alpha_{g} \rho_{g} Y_{i, g}\right)}{\partial t}+\nabla\left(\alpha_{g} \rho_{g} \vec{u}_{g} Y_{i, g}\right)=-\nabla \cdot \alpha_{g} \vec{J}_{i, g}+\left(\dot{m}_{i, g s_{2}}-\dot{m}_{i, s_{2} g}\right)+R_{i, g} \\
& \vec{J}_{i, g}=-\left(\rho_{g} D_{i, g}+\frac{\mu_{t}}{S c_{t}}\right) \nabla Y_{i, g}-D_{T, i, g} \frac{\nabla T}{T}
\end{aligned}
$$

where $Y_{i, g}=1,2, \ldots n_{g}$ is the mass fraction of species $i$ in the gas phase, $\vec{J}_{i, g}$ is diffusion flux of species $i, \dot{m}_{i, g s_{2}}$ and $R_{i, g}$ are the mass transfer between the gas and biomass phase due to drying and devolatilization reaction (pyrolysis) respectively. $D_{i, g}$ is the mass diffusion coefficient for species $i$ in the gas phase, and $D_{T, i, g}$ is the thermal diffusion coefficient. 
The heat balance equation for the gas phase is given by

$$
\begin{aligned}
\frac{\partial\left(\alpha_{g} \rho_{g} h_{g}\right)}{\partial t}+ & \nabla\left(\alpha_{g} \rho_{g} \vec{u}_{g} h_{g}\right) \\
& =\alpha_{g} \frac{\partial P_{g}}{\partial t}+\overline{\bar{\tau}}_{g}: \nabla \vec{u}_{g}-\vec{q}_{g}+S_{g}+Q_{g s_{1}}+Q_{g s_{2}}+\left(\dot{m}_{s_{2} g} h_{s_{2} g}-\dot{m}_{g s_{2}} h_{g s_{2}}\right)
\end{aligned}
$$

where $h_{g}$ is the specific enthalpy of the gas phase, $\vec{q}$ is the heat flux, $S$ is a source term that includes enthalpy due to chemical reaction, $Q_{g s_{1}}$ is the intensity of heat exchange between the gas and solid phases. The last term on the right side represent the interphase enthalpy exchange due to evaporation.

The heat balance equations for the solid phase is given by

$$
\begin{gathered}
\frac{\partial\left(\alpha_{s_{1}} \rho_{s_{1}} h_{s_{1}}\right)}{\partial t}+\nabla\left(\alpha_{s_{1}} \rho_{s_{1}} \vec{u}_{s_{1}} h_{s_{1}}\right)=\alpha_{s_{1}} \frac{\partial P_{s_{1}}}{\partial t}+\overline{\bar{\tau}}_{s_{1}}: \nabla \vec{u}_{s_{1}}-\vec{q}_{s_{1}}+Q_{s_{1} g} \\
\frac{\partial\left(\alpha_{s_{2}} \rho_{s_{2}} h_{s_{2}}\right)}{\partial t}+\nabla\left(\alpha_{s_{2}} \rho_{s_{2}} \vec{u}_{s_{2}} h_{s_{2}}\right)=\alpha_{s_{2}} \frac{\partial P_{s_{2}}}{\partial t}+\overline{\bar{\tau}}_{s_{2}}: \nabla \vec{u}_{s_{2}}-\vec{q}_{s_{2}}-S_{g}+ \\
Q_{s_{2} g}+\left(\dot{m}_{g s_{2}} h_{g s_{2}}-\dot{m}_{s_{2} g} h_{s_{2} g}\right)
\end{gathered}
$$

The intensity of the heat exchange between the gas and solid phase is given by:

$$
Q_{s_{i} g}=h_{s_{i} g}^{\prime} A_{i}\left(T_{s_{i}}-T_{g}\right)
$$

where $h_{g s_{i}}^{\prime}, A_{i}$ and $\left(T_{s_{i}}-T_{g}\right)$ are the volume heat transfer coefficient between the gas phase and the $i$ th solid phase (sand or biomass), the gas-solid interface contact area and the temperature difference between the bulk gas and the solid. The heat transfer coefficient is related to the Nusselt number, $N u_{s_{i}}$, as follows:

$$
h_{s_{i} g}^{\prime}=\frac{\kappa_{g} N u_{s_{i}}}{d_{s_{i}}}
$$

where $\kappa_{g}$ is the thermal conductivity of gas phase and $d_{s_{i}}$ is the particle diameter of the $i$ th solid phase. Nusselt number is given by Gunn's correlation [34], applicable to a porosity range of $0.35-1.0$ and Reynolds number of up to $10^{5}$, as follows:

$$
\begin{aligned}
N u_{s_{i}}=\left(7-10 \alpha_{g}+5 \alpha_{g}^{2}\right)\left(1+0.7 \operatorname{Re}_{s_{i}}^{0.2} \operatorname{Pr}^{1 / 3}\right) \\
+\left(1.33-2.4 \alpha_{g}+1.2 \alpha_{g}^{2}\right) \operatorname{Re}_{s_{i}}^{0.7} \operatorname{Pr}^{1 / 3}
\end{aligned}
$$

It is worth noting that in the above heat balance equations it is assumed that the internal thermal resistance at the single particle level is negligible, i.e. uniform 
temperature distribution is assumed. The estimated Biot numbers ${ }^{*}$ for the sand and biomass particles used in this study are well below unity $(0.087$ and 0.16$)$ respectively), thus lending support to the validity of this assumption.

In developing the above equations, it is assumed that the biomass particle retain its original size while the density changes due to devolatilization and drying to produce the bio-char and gas. It is recognized that this is an oversimplification of a more complex phenomena where it is expected that biomass particle undergoing thermal conversion in a fluidized bed are prone to defragmentation and shrinkage. However, within an Eluerian-Eluerian modelling, a well-established approach to model theses phenomenon is not yet available. Recalling the results of the solid-gas separation using the novel separation mechanism presented in the first part of this study [7], where it was found that the separation efficiency is critically sensitive to the particle size, the simplification discussed above may result in over prediction of the separation efficiency. Apart from that, no critical effect on the overall pyrolysis product is expected.

\subsection{Biomass drying and devolatilization}

\subsubsection{Drying}

Several biomass drying models are available in the literature. Syamlal and Bisset [35] and Tinaut et al [36] reported a model treating the biomass drying step as a chemical reaction with kinetic rate constants obtained from Arrhenius law. Lee et al [37] and Di Blasi [38] reported that the biomass drying can be treated as an evaporation/condensation process where the moisture evaporation is controlled by diffusion. A different and a simpler method, reported by Gerber et al. [39], assumed that the biomass entering the reactor contains no water and then added the moisture truly existing in the biomass to the inlet in the form of gaseous water. In this study, the biomass drying is implemented in the model based on evaporative mass transfer process where the biomass water content is assumed to be converted to moisture and added to the gases phase according to the following mass transfer equation [37]:

\footnotetext{
${ }^{*}$ Assuming an average surrounding temperature of $500{ }^{\circ} \mathrm{C}$, heat transfer coefficient of $0.65 \mathrm{~kW} \mathrm{~m}^{-2} \mathrm{~K}^{-}$ ${ }^{1}$, thermal conductivity of 0.25 and $0.1 \mathrm{Wm}^{-1} \mathrm{~K}^{-1}$ for sand and biomass particles respectively.
} 
$m_{l v}=k_{m} \times \alpha_{l} \rho_{l} \frac{\left(T_{l}-T_{s a t}\right)}{T_{\text {sat }}}$

where $m_{l v}$ is the mass transfer rate from the liquid phase to the vapour phase per unit volume, $k_{m}$ is the mass transfer coefficient, $\alpha_{l}$ and $\rho_{l}$ represent the moisture volume fraction and density, respectively, $T_{l}$ is the gaseous phase temperature and $T_{\text {sat }}$ is the saturation temperature taken as $100{ }^{\circ} \mathrm{C}$. In the energy balance (Eqs. 14 and 16) the enthalpy due to drying is calculated by multiplying the mass transfer rate by the latent heat of evaporation.

\subsubsection{Devolatilization}

The biomass is treated as a solid phase consisting of volatile matters, fixed carbon, ash and fixed water content. The composition of the biomass (switch grass), obtained from proximate analysis, is given in Table. 3 . In adding the devolatilization to the model, there are three options that can be broadly classified under the following mechanisms: (i) one step global reaction model (e.g. [22]) (ii) one component with parallel reactions model (e.g. [10]) (iii) multicomponent reactions model (e.g. [20, 23, 26]). The first option is the simplest and assumes that the biomass is thermally degraded to a final product of char, condensable vapour (bio-oil) and a permanent gas (NCG) and this can be represented by a single first order reaction and one global rate constant. Further details on this are given below. The second option, widely known as the Waterloo concept [34], assumes that the pyrolysis proceed by first producing char, primary oil and gas, which is then followed by a secondary reaction converting the primary oil to secondary products of permanent gas and bio-oil. These parallel reactions are commonly presented as a set of four first order competing reactions, each with different rate constants (e.g. [34, 40]). The third model is a more complex, commonly referred to as multi component pyrolysis model. This involves treating the biomass as a multicomponent, in most cases considered as hemicellulose, cellulose and lignin. Each component is assumed to be thermally degraded independent of each other and with different rate constants to produce biooil, gas (NCG) and char (e.g. [9], [27]).

In this study, a one-global reaction scheme is used to for the formation of various pyrolysis products as follows [22]: 


$$
\text { BIOMASS } \rightarrow \alpha_{1} \mathrm{CHAR}+\alpha_{2} \text { BIO.OIL }+\alpha_{3} \mathrm{H}_{2} \mathrm{O}+\alpha_{4} \mathrm{H}_{2}+\alpha_{5} \mathrm{CO}+\alpha_{6} \mathrm{CO}_{2}+\alpha_{7} \mathrm{CH}_{4}
$$

where $\alpha_{i}$ is the stoichiometric coefficient of reaction. As shown, the overall pyrolysis products are assumed to consist of char, condensable vapour (bio-oil) and a permanent gas phase (NCG) consisting of $\mathrm{H}_{2}, \mathrm{CO}, \mathrm{CO}_{2}$ and $\mathrm{CH}_{4}$. This modeling scheme has the advantage of being computationally fast, especially when handling complex multiphase solid system in three dimensional coordinates. It also serves the main purpose of this study which is to provide a robust and realistic predictive tool for the evaluation of the reactor performance and aid in future design and development of the process. The stoichiometric coefficients $\left(\alpha_{i}\right)$ for switch grass pyrolysis reaction have been derived previously by Boateng and Mtui [22] as shown in Table.4. These are obtained from molar elemental balances of carbon, hydrogen and oxygen in the switch grass and the corresponding composition of the pyrolysis products of bio-oil, gas and char obtained from a TGA analysis. Further details on the derivation of the stoichiometric coefficients can be found in the literature [22, 41, 42].

The rate of the pyrolysis reaction in Eq. 21 is given by the following formula, specifically derived for switch grass pyrolysis by Pasangulapati [43] as follows:

$r=k \alpha_{s_{2}}\left[C_{\text {vol }}\right]^{0.67}$

where $C_{v o l}$ is the concentration of the volatiles in the biomass and $k$ is the reaction rate constant given by an Arrhenius kinetic format as follow:

$k=A \exp [-E / R T]$

were the pre-exponential factor $A$ and the activation energy $E$ used are $2.16 \times 10^{7} \mathrm{~s}^{-1}$ and $1.037 \times 10^{8} \mathrm{~J} / \mathrm{Kmol}$ respectively [43].

\subsection{Computation procedure and boundary conditions}

The model equations were solved using the finite volume approach. First-order discretization schemes were used for the solution of the convection terms in all governing equations. The relative error between any two successive iterations was specified by using a convergence criterion of $10^{-3}$ for each scaled residual component. The phase-coupled SIMPLE (PC-SIMPLE) algorithm [44], which is an extension of the SIMPLE algorithm to multiphase flows, was applied for the pressurevelocity coupling. The linearized governing equations were solved using block algebraic multi-grid method. 
In order to avoid numerical instabilities and ensure capturing the fast biomass conversion and heat transfer, the solution time step for the reactive system was set to a relatively smaller time step of $0.0005 \mathrm{~s}$ for the first real processing time of $0.5 \mathrm{~s}$ then increased to $0.001 \mathrm{~s}$ for the rest of the simulation time. In Part I of this study, it was shown that a time step of $<0.005 \mathrm{~s}$ is sufficient to satisfy the Courant-FriedrichsLewy (CFL) condition for accurate solution [7]. The maximum allowable number of iterations per time step was set at 20 . The product gaseous yield was monitored and recorded at the reactor gas outlet after reaching steady condition. In setting the boundary conditions, the tip of the gas outlet was set at atmospheric pressure. At the walls, no-slip wall condition was specified for the gas phase and a slip velocity and granular temperature was specified for the solid phase using Johnson and Jackson $[45,7]$ boundary equations. For the thermal boundary conditions, all the walls were treated as adiabatic by setting zero heat flux between the reactor and its surroundings.

The computer used in the simulation was an HP Z800 Workstation (3.20 Ghz 4 Core processor with 24GB RAM). The total time required to reach steady state operation of the pyrolysis reactor (defined in terms of stable product yield) was around 2.5 seconds. The computation time for $1 \mathrm{~s}$ real processing time was $7.7 \mathrm{hr}$, which is considerably realistic compared to some of the recently reported CFD simulation time for similar problems, e.g. Mellin et al. [26] reported a processing time of around $66 \mathrm{hr}$ for each $1 \mathrm{~s}$ real processing time.

\section{Results and discussion}

\subsection{Separation efficiency}

The percentage efficiency of the gas separation from the solid-gas phase mixture, $\eta_{\text {sep }}$, was calculated from the specified inlet solid flow rate, $m_{i n}$, and the predicted solid entrainment rate at the gas exit pipe, $m_{\text {out }}$, as follows [7]:

$$
\eta_{\text {sep }}=\left(1-\frac{m_{\text {out }}}{m_{\text {in }}}\right) \times 100 \%
$$

Fig. 2 shows the temporal histories of separation efficiency for both biomass and sand from the pyrolysis gas. The data was obtained by recording the solid particles 
entrainment rate for each solid phase at the tip of the gas exit during pyrolysis. There is a delay of $\sim 1.0 \mathrm{~s}$ before the particulate phase reach the tip of the gas exit pipe, which is why $100 \%$ efficiency is seen before this time has elapsed. The sharp fluctuation in the separation efficiency are due to start-up effect and are shown to last for few second, before the flow reaches hydrodynamic stability in around $4.0 \mathrm{~s}$. This coincides with the time required to reach overall steady state of the reactor defined in terms of the pyrolysis gas flow rate, as discussed in Section 4.5. The calculated separation efficiency for the sand and biomass particles after $5 \mathrm{~s}$ operation was found to be $99.97 \%$ and $99.95 \%$ respectively. This is in good agreement with the experimental and model prediction data presented in Part I of this study [7].

\subsection{Temperature distribution and heat transfer}

Figs. 3 and 4 show the contour plot and profile of the cross-sectional average temperature for the three phases of the pyrolysis gas, sand and bio-char after $5 \mathrm{~s}$ operation. The heat-bearing sand is introduced at the top of the reactor at a very high temperature of $700{ }^{\circ} \mathrm{C}$ and then rapidly losses heat to the surrounding nitrogen and biomass particles, both entering at $25{ }^{\circ} \mathrm{C}$. In the model formulations, the particleparticle heat transfer is assumed negligible due to the low concentrations of solids; therefore, the predicted heat transfer to the biomass is mainly by convection through the nitrogen gas carrier. It is clear that due to the rapid heat transfer at the entrance, the thermal entrance length for the biomass particles is relatively short. However, the overall thermal equilibrium between the various phases is only reached after around $100 \mathrm{~cm}$ from the reactor entrance due to the developing heat transfer between the sand and nitrogen. All phases appear to attain almost a constant temperature of around $400{ }^{\circ} \mathrm{C}$ at the region where the cone deflector and gas discharge pipe are located. In Fig. 4, the contours show uniform radial and axial temperature distribution throughout the lower part of the reactor. Such a stable range of temperature is highly desirable to ensure optimum condition for high bio-oil yield, while fast separation of the product from the bio-char takes place. Previous experimental studies have shown that over-heated biomass will produce more non-condensable gas than bio-oil [e.g. 4].

The contours of solids concentration and the pyrolysis reaction rate after $5 \mathrm{~s}$ operation are shown in Fig. 5. Both the biomass and sand particles are highly 
concentrated within the thermal entrance zone, meanwhile the pyrolysis reaction rate is very limited, nearly zero at the far top of the reactor due to low biomass temperature. The devolatilization rate then becomes uniform as the biomass enters the relatively thermally stable zone with temperature just above $400^{\circ} \mathrm{C}$. It should be noted that the devolatilization rate is also dependent on the availability of biomass within a given zone; hence it is a combination of the temperature and biomass concentration that determines the localized gas production rate. In the far bottom part of the reactor, beyond the gas exit pipe, the devolatilization rate decreases mainly due to the drop in temperature below $400^{\circ} \mathrm{C}$.

\subsection{Gas residence times}

As noted earlier, in order to increase the bio-oil yield in the pyrolysis product gas, it is very important to control the reactor temperature and residence time to avoid secondary cracking reactions. A downer reactor has the advantage of operating at nearly plug flow, thus limiting the spread of the gas/solid residence time distribution. Fig. 6 shows the gas velocity vector after $5 \mathrm{~s}$ operation (steady state condition). It is clear that the gas velocity takes the shape of a plug flow at the upper part before the separator. In the region just below the separator, there is a noticeable reverse flow towards the gas exit pipe due to the migration of gas from the higher pressure zone to the tip of the gas exit pipe, where the pressure is set at atmospheric. Therefore, the gas residence time is directly related to the distance travelled beyond the gas exit pipe. In part I of this study [7], the influence of the various operating conditions on the gas residence time was investigated through the analysis of the gas disengagement height (GDH). The DGH was defined as the distance travelled by the gas below the gas-solid separator before reversing flow towards the gas exit pipe. Accordingly, with the knowledge of the gas velocity one can relate this to the distance travelled by gas to extract approximate data on the residence time. In this part of the study, another numerical approach to determine the gas residence time, based on tracking a single massless particle, has been used. This method is also referred to in the literature as particle tracking or trajectory calculation (e.g. [26], [46]). The tracking method was implemented in ANSYS-FLUENT platform to monitor the velocity field of the gas phase. A numerical example is shown in Fig. 7, where 50 mass-less particles were released from the top inlet. In total around 500 were released at different points from the biomass inlet (where residence time $=0$ ). Most of particles $(>90 \%)$ reached the 
outlet while other particles remained circulating within the reactor. The predicted residence time distribution (RTD) within the downer reactor is shown in Fig. 8. Due the various path lines along the gas flow field, the RTD shows a narrow distribution within the range of $0.6-1.4 \mathrm{~s}$ and a dominant peak at $0.9 \mathrm{~s}$. This is satisfactory close to the recommended residence time for high bio-oil yield, which is within the range of $1-2 \mathrm{~s}[2,6]$.

\subsection{Devolatilization efficiency}

Within the temperature range of $400-550^{\circ} \mathrm{C}$, most of the volatiles are believed to be removed from the biomass by devolatilization to produce a pyrolysis gas and biochar. The bio-char mainly consist of the remaining volatiles, ash and fixed carbon. Beside the temperature, the devolatilization efficiency is strongly dependent on a number of factors, including the biomass particle size, heating rate and residence time within the hot zone of the reactor. The formula used to calculate the devolatilization efficiency is given by,

$$
\eta_{\text {dev }}=\frac{m_{\text {volatile }} \text { removed from biomass }}{m_{\text {volatile }} \text { in the biomass feed }}
$$

Fig. 9 shows the predicted cross-section averaged devolatilization efficiency after 5 seconds operation as function of the reactor height. It is clear that the devolatilization rapidly progresses as the biomass particles fall towards the bottom of the reactor. The efficiency approaches constant value of $62.0 \%$ at the bottom exit of the reactor. At the gas exit pipe the efficiency is around $58 \%$ and the corresponding predictions of the overall product yield (bio-oil, bio-char and NCG) are discussed in the next section.

\subsection{Product yield and composition}

Fig. 10 shows the evolution of the pyrolysis gaseous products including condensable gases $\left(\mathrm{H}_{2} \mathrm{O}\right.$, Bio-oil) and non-condensable gases $\left(\mathrm{CO}, \mathrm{CO}_{2}, \mathrm{CH}_{4}\right.$ and $\left.\mathrm{H}_{2}\right)$. Note that the gas composition is obtained at the tip of the gas exit pipe. It is clear that all of the pyrolysis gaseous components, with the exception of water vapour, increase steadily during the unsteady stage. The water vapour appears to be instantaneously released as a result of fast biomass drying, and this constituted $100 \%$ composition of the gas 
phase during the first half second of the start-up. The water vapour then gradually decreases to steady concentration as the other volatile components start to increase. This behaviour is consistent with the mechanism of biomass pyrolysis where drying occurs first at a low temperature of $100{ }^{\circ} \mathrm{C}$ and at a fast rate while de-volatilization takes place at a later stage at a temperature beyond $\sim 200^{\circ} \mathrm{C}$. The pyrolysis gas flow rate sharply increases within the first second and then becomes steady after around $4 \mathrm{~s}$, which is around the time the overall flow hydrodynamics becomes stable as shown earlier in terms of the solid-gas separation efficiency in Fig. 2.

Fig. 11 shows the steady state composition of the overall pyrolysis products (bio-oil, bio-char and NCG) and the composition of the NCG predicted in this study in comparison with some of the recent reported experimental studies. It is recognised that the operating principles and conditions of these literature studies are different than the ones considered in the present study; however, the comparison made here is only meant to show confidence on the validity of the modelling approach and demonstrate its predictive capabilities as a promising design and development tool. In Fig. 11a the comparison with the experiemental work of Ding et al. [47] shows the best agreement with the current predictions in terms of the overall product composition of the bio-oil, char and NCG. This experiement was carried out in the downer side of a dual fluidized bed stystem, with the heat supplied to the pyrolysis reactor from a connected comustor, thus greatly resemple the case simulated here. The composition of the biomass used was also closely matching the proximate anlaysis of the swicth grass used in the current simulation. The data reported by Punsuwan and Tangsathitkulchai [48], which was alos produced in a downer reacor, shows clear discribancy when compared to the current predictions. This is mainly attributed to the very short biomass residence time within the heated section of the reactor, which was just limited to $20 \mathrm{~cm}$ of the total $1.1 \mathrm{~m}$ downre height. Such a reactor design, while having the advantage of controling the residnce time of the pyrolysis gas within the hot section of the reactor, has a damaging effect on the amount of volatiles released. In the experimental data of Boateng and Mtui [22], which was produced in a bubbling bed with the same feedstock used in this study, the bio-oil yield is close to the value predicted here, however, the char is considerably low and the NCG is high. This is not surmising and agrees well with the reported literature, since in a bubbling bed reactor the residence time of the char is 
relatively high compared to fast solid circulating system $[4,49]$. This in turn results in higher biomass decomposition to vapour, which when in contact with the char produces more NCG due to char catalytic cracking. In the reactor simulated in this study, the effect of the char cracking is eliminated because the reactor is equipped with a fast gas separation mechanism that allows limiting the gas residence time and its contact with the char.

It should be note that the calculated bio-oil yield includes the produced water. In this study, the water content was found to represent $11.0 \mathrm{wt} \%$ of the total liquid product. None of the literature reported in Fig. 11a have given the exact fraction of water in the product oil, but a study by Westerhof [50] reported that typically water content in the pyrolysis bio-oil is in the range of $15-35 \mathrm{wt} \%$ water content. The low water content in the product predicted here is mainly due to the low moisture content in the feedstock. The calculated HHV of the bio-char and NCG were found to be 29.85 and $9.56 \mathrm{MJ} / \mathrm{kg}$ respectively. These values are within the ranges reported for biomass fast pyrolysis [51-53].

Comparison of the predicted and experimentally measured non-condensable gas (NCG) composition, shown in Fig. 11b, indicate a satisfactory agreement with the experimental data of Ding et al. [47], with the exception of $\mathrm{H}_{2}$, which is clearly underpredicted. The comparison with the experimental data of Boateng and Mtui [22], is also indicate satisfactory agreement in terms of $\mathrm{CO}$ and $\mathrm{CO}_{2}$ concentration, despite of it being produced in a different reactor type, but the deviation in $\mathrm{CH}_{4}$ and $\mathrm{H}_{2}$ reaches up to $90 \%$. It is generally expected that the NGC gas composition for a given biomass material should not be highly sensitive to the reactor type (e.g. bubbling or downer) as long as the operating conditions are close and the gas residence time is well controlled to avoid char/thermal cracking. However, it is recognized that biomass pyrolysis is a complex phenomenon and such a control during experiments is not always granted. Another factor that may have contributed to discrepancy between the predicted NCG composition and the experimental measurement is the simplifications applied in determining the fitting parameters used in the pyrolysis reaction (Eq. 21), as previously reported by Boateng and Mtui [22]. 


\section{Conclusion}

This study presented a robust CFD model for the simulation of fast pyrolysis of biomass in a downer reactor equipped with a novel gas-solid separation mechanism. The highly endothermic reaction was assumed to be driven by an inert heat carrier introduced to the top of the reactor from a combustor within a dual fluidized bed reactor. The pyrolysis predictive model, which was based on the Eulerian-Eulerian (two-fluid) hydrodynamic model developed in part I of this study, was implemented using a single pyrolysis reaction and was solved in three dimensional coordinates using ANSYS-FLUENT commercial software. According to the predicted results, the following conclusions are made:

a) Despite the high complexity of the pyrolysis process, the proposed model proved to be computationally fast and reasonably accurate, thus has the great potential for parametric analysis or as tool for design, optimization and scale-up analysis of the pyrolysis reactors.

b) The proposed novel solid-gas separation mechanism has the potential to achieve $>99.9 \%$ separation efficiency, while allowing control of the pyrolysis gas residence time within $2 \mathrm{~s}$.

c) The multi-phase flow mixture show uniform temperature distribution along the reactor height, and most importantly, the temperature profile confirm a short thermal entrance length, a highly desirable feature for fast pyrolysis of biomass.

d) The predicted pyrolysis yield $(56.85 \%$ bio-oil, $37.87 \%$ char, and $5.28 \%$ NCG) and gas composition (41.54\% $\mathrm{CO}_{2}, 51.41 \% \mathrm{CO}, 0.32 \% \mathrm{H}_{2}$ and $6.73 \% \mathrm{CH}_{4}$ ) suggest that the applied single global pyrolysis reaction and the new kinetic parameters used are capable of producing satisfactory data.

e) The new developed user defined function (UDF), presented in Appendix A, can be incorporated in CFD codes for the simulation of fast pyrolysis of various biomass materials, once the pyrolysis kinetics are known. 


\section{Notations}

\begin{tabular}{|c|c|}
\hline$A_{i}$ & Interfacial area $\left(\mathrm{m}^{2}\right)$ \\
\hline$C_{p}$ & Specific heat $\left(\mathrm{J} \mathrm{kg}^{-1} \mathrm{~K}^{-1}\right)$ \\
\hline$d_{i}$ & Diameter of solid phase $i(\mathrm{~m})$ \\
\hline E & Activation energy (-) \\
\hline$\vec{g}$ & Gravity $\left(\mathrm{m} \mathrm{s}^{-2}\right)$ \\
\hline$h$ & Specific enthalpy $\left(\mathrm{kJ} \mathrm{kg}^{-1}\right)$ \\
\hline$h^{\prime}$ & Heat transfer coefficient $\left(w^{2}{ }^{2} k^{-1}\right)$ \\
\hline$k_{m}$ & Mass transfer coefficient $\left(\mathrm{s}^{-1}\right)$ \\
\hline$H_{\text {feed }}(T)$ & Heat of formation for feedstock at temperature $T(\mathrm{KJ} / \mathrm{kg})$ \\
\hline$H_{\text {prod }}(T)$ & Heat of formation for product at temperature $\mathrm{T}(\mathrm{KJ} / \mathrm{kg})$ \\
\hline$\Delta H_{f, 298}^{\circ}$ & Heat of formation at temperature $298 \mathrm{~K}(\mathrm{KJ} / \mathrm{kg})$ \\
\hline$\vec{J}_{i, g}$ & Diffusion flux of species $i\left(\mathrm{~kg} \mathrm{~m}^{-2} \mathrm{~s}^{-1}\right)$ \\
\hline$L$ & Reactor length $(\mathrm{m})$ \\
\hline$m_{\text {in }}, m_{\text {out }}$ & Mass of fed and entrained solid particles respectively $(\mathrm{kg})$ \\
\hline$\dot{m}$ & Mass transfer $\left(\mathrm{kg} \mathrm{m}^{-3} \mathrm{~s}^{-1}\right)$ \\
\hline$N u_{s_{i}}$ & Nusselt number of solid phase $i(-)$ \\
\hline$P$ & Pressure (pa) \\
\hline $\operatorname{Pr}$ & Prandtl number (-) \\
\hline$\vec{q}$ & Heat flux $\left(w^{-3}\right)$ \\
\hline$Q_{g s_{1}}$ & Intensity of heat exchange between gas and solid $\left(\mathrm{kJ} \mathrm{m}^{-3} \mathrm{~s}^{-1}\right)$ \\
\hline$Q_{\text {in }}$ & Required thermal input for pyrolysis $(\mathrm{Kw})$ \\
\hline$R_{g}, R_{S_{i}}$ & Interphase mass transfer term $\left(\mathrm{kg} \mathrm{m}^{-3} \mathrm{~s}^{-1}\right)$ \\
\hline$R e_{s_{i}}$ & Reynolds number of solid phase $i(-)$ \\
\hline
\end{tabular}


Time (s)

$\vec{u}_{g}, \vec{u}_{s_{i}}$

Gas and solid velocity vector $\left(\mathrm{m} \mathrm{s}^{-1}\right)$

$U_{m f}$

Minimum fluidization velocity $\left(\mathrm{m} \mathrm{s}^{-1}\right)$

$U_{p}$

Particle velocity $\left(\mathrm{m} \mathrm{s}^{-1}\right)$

$Y_{i, g}$

Mass fraction

\section{Greek symbols}

$\begin{array}{ll}\alpha_{g}, \alpha_{s_{i}} & \text { Volume fraction of gas and solid phase } i \text { respectively (-) } \\ \beta & \text { Momentum exchange coefficient }\left(\mathrm{kg} \mathrm{m}^{-3} \mathrm{~s}^{-1}\right) \\ \gamma_{\Theta_{s_{i}}} & \text { Collisional energy dissipation }\left(\mathrm{kg} \mathrm{m}^{-1} \mathrm{~s}^{-3}\right) \\ \eta & \text { Separation efficiency }(-) \\ \Theta_{s_{i}} & \text { Granular temperature of solid phase } i\left(\mathrm{~m}^{2} \mathrm{~s}^{-2}\right) \\ \kappa_{\Theta_{s_{i}}} & \text { Diffusion coefficient of granular energy }\left(\mathrm{kg} \mathrm{m}^{-1} \mathrm{~s}^{-1}\right) \\ \lambda_{s_{i}} & \text { Particle bulk viscosity }\left(\mathrm{kg} \mathrm{m} \mathrm{m}^{-1}\right) \\ \rho_{s_{i}}, \rho_{g} & \text { Solid and gas densities respectively }\left(\mathrm{kg} \mathrm{m}^{-3}\right) \\ \tau & \text { Solid residence time }(\mathrm{s}) \\ \overline{\bar{\tau}} & \text { Shear stress tensor }\left(\mathrm{kg} \mathrm{m} \mathrm{m}^{-1}\right)\end{array}$

\section{Acknowledgement}

The authors from the UK thank The Leverhulme Trust for a research grant (RPG410).

\section{Appendix A}

\#include "udf.h" \#include "stdio.h" \#include "time.h" \#define SMALL_S 1.e-29 \#define eps_g_small 0.99999 \#define spe_small 1.e-8 \#define TMĀX 2500. 
static const real Arrhenius_devolatilization $=2.16 \mathrm{e}+7$;

static const real E_Activation_devolatilization $=10.37 e+7$;

static const real c_devol_pre $=1$., c_devol_exp $=1$;

static cxboolean init_flag = TRUE;

$1 *$ Search the index for each species *I

static real mw[MAX_PHASES][MAX_SPE_EQNS];

static int INDEX_PHASE_CH4 $=0$, INDEX_SPECIES_CH4 $=0$, INDEX_PHASE_CO $=0$, INDEX_SPËCIES_CO $=0$, INDEX_PHASE_CO2 $=0$, INDEX_SPECIES_CŌ2 $=$ 0 , INDEX_PHASE_H2 $=0$, INDEX_SPECCIES_H2 $=0$, INDEX_PHASE_H2O $=0$, INDEX_SPECIES_H2O $=0$, INDEX_PHASE_N2 $=0$, INDEX_SPECIES_N2 $=0$, INDEX_PHASE_TAR $=0$, INDEX_SPECIES_TAR $=0$, INDEX_PHASE_C $=0$, INDEX_SPECIES $C=0$, INDEX_PHASE_VOL $=0$, INDEX_SPECIES $\bar{V} \overline{\text { VI }}=0$, INDEX_PHASE MOISTURE $=0$, INDEX_SPECIES MOISTURE $=0$,

INDEX PHASE ASH $=0$, INDEX SPECIES ASH $=0$;

DEFINE_ADJUSTT(Devolatilization,domain)

\{int n, ns;Domain *subdomain;

/*int n_phases = DOMAIN_N_DOMAINS(domain); ${ }^{*}$

if(init_flag)

\{\#if !RP_HOST

$l^{*}$ search all the species and saved the Molecular Weight */

sub_domain_loop(subdomain, domain, $\mathrm{n}$ )

\{Material *m_mat, *s_mat;

if (DOMAIN_NSPE(subdomain) $>0$ )

$\{$ m_mat $=$ Pick_Material(DOMAIN_MATERIAL_NAME(subdomain),NULL);

mixture_species_loop(m_mat,s_mat,ns)

\{if (0 =- strcmp(M̄IXTURE_SPECIE_NAME(m_mat,ns),"ch4"))

\{INDEX_PHASE_CH4 =n;INDEX_SPECIES_CH4 =ns; $\}$

else if $\left(\overline{0}==\operatorname{strcmp}\left(M I X T U R E \_S P E C I E \_N A \bar{M} E\left(m \_m a t, n s\right), " c o "\right)\right)$

$\{$ INDEX_PHASE_CO $=\mathrm{n}$; INDEXX_SPECIES_CO $=\mathrm{ns} ;\}$

else if $\left(\overline{0}==\operatorname{strcm} p\left(M I X T U R E \_S P E C I E \_N A \bar{M} E\left(m \_m a t, n s\right), " c o 2 "\right)\right)$

\{INDEX PHASE CO2 = n;INDEX SPECIES CO $2=n s ;\}$

else if $\left(\overline{0}==\operatorname{strcmp}\left(M I X T U R E \_S P E C I E \_N A M E\left(m \_m a t, n s\right), " h 2 "\right)\right)$

$\{$ INDEX_PHASE_H2 $=\mathrm{n}$;INDEX_SPECIES_H2 $=\overline{\mathrm{n}}$; $\}$

else if $(\overline{0}==$ strcmp(MIXTURE_SPECIE_NAME(m_mat,ns),"h2o"))

\{INDEX_PHASE_H2O =n;INDEX_SPEC̄IES_H2O $=\mathrm{ns} ;\}$

else if $\left(\overline{0}==\operatorname{strcmp}\left(M I X T U R E \_S P E C I E \_N A M E\left(m \_m a t, n s\right), " o 2 "\right)\right)$

$\{$ INDEX_PHASE_O2 $=\mathrm{n}$;INDEX_SPECIES_O2 $=\bar{n} \mathrm{~s} ;\}$

else if $\left(\overline{0}==\operatorname{strcmp}\left(M I X T U R E \_\right.\right.$SPECIE_NAME $\left.\left.\left(m \_m a t, n s\right), " n 2 "\right)\right)$

$\{$ INDEX_PHASE_N2 $=\mathrm{n}$;INDEX_SPECIES_N2 $=\overline{\mathrm{n}} ;$; $\}$

else if $\left(\overline{0}==\operatorname{strcmp}\left(M I X T U R E \_\right.\right.$SPECIE_NAMME(m_mat,ns),"tar"))

$\{$ INDEX_PHASE_TAR $=\mathrm{n}$;INDEX SPECIES_TAR $=\mathrm{ns} ;\}$

else if $\left(\overline{0}==\operatorname{strcmp}\left(M I X T U R E \_S P E C I E \_N A M E\left(m \_m a t, n s\right), " c "\right)\right)$

IINDEX_PHASE_C $=\mathrm{n} ;$ INDEX_SPECIES_C $=\mathrm{ns} ;\}$

else if ( $0==$ strcmp(MIXTURE_SPECIE_NAME(m_mat,ns),"volatile"))

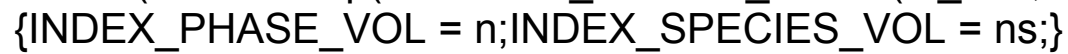

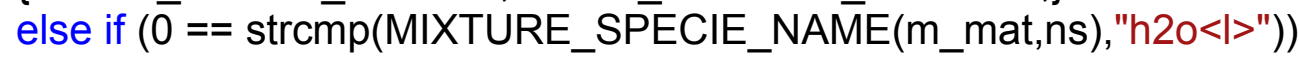

$\{$ INDEX_PHASE_MOISTURE $=\mathrm{n} ;$ INDEX_SPECIES_MOISTURE $=\mathrm{ns} ;\}$

CX_Message ("In ---

$\% d, \% d \% d, \% d \% d, \% d \% d, \% d \% d, \% d \% d, \% d \% d, \% d \% d, \% d \% d, \% d \% d, \% d \%$ $\mathrm{d}, \% \mathrm{~d} \% \mathrm{~d}, \% \mathrm{~d} \% \mathrm{~d}, \% \mathrm{~d} \% \mathrm{~d}, \% \mathrm{~d} \% \mathrm{~d}$ In",INDEX_PHASE_CO2, 


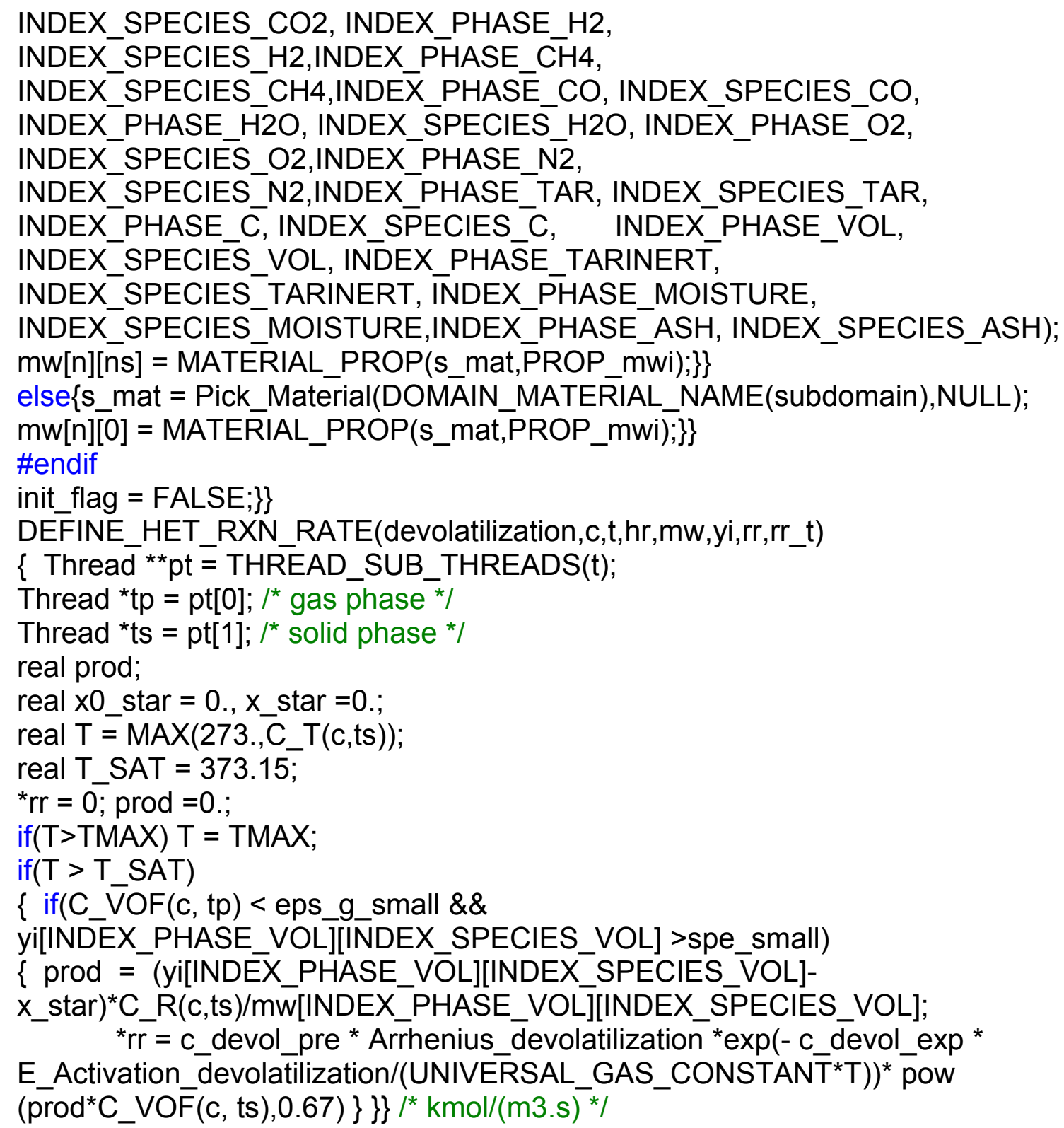

\section{References}

[1] D. A. Laird, R. C. Brown, J. E. Amonette and J. Lehmann, Review of the pyrolysis platform for coproducing bio-oil and biochar, Biofuels, Bioproducts and Biorefining, 3 (2009) 547-562

[2] A. V. Bridgewater, D. Meier, D.Radlein, An overview of fast pyrolysis of biomass, Organic Geochemistry 30 (1999) 1479-1493

[3] A. V. Bridgewater, P. Carson and M. Coulson, A comparison of fast and slow pyrolysis liquids from mallee. Int. J. Global Energy Issues, 27(2007) 204-216

[4] M. I. Jahirul, M. G. Rasul, A. A. Chowdhury, N. Ashwath, Biofuels Production through Biomass Pyrolysis-A Technological Review, Energyies, 5 (2012) 49525001 
[5] P. Basu, Biomass gasification, pyrolysis and torresfaction: practical design and theory, (2013) Second edition, Published by Elsevier Inc, ISBN: 978-0-12-396488-5.

[6] D. Mohan, C.U. Pittman and P.H. Steele. Pyrolysis of wood/biomass for bio-oil: A critical review. Energy and Fuels 20 (2006), 848-889.

[7] X. Yu, Y. Makkawi, R. Ocone, M. Huard, C. Briens and F Berruti, A CFD study of biomass pyrolysis in a downer reactor equipped with a novel gas-solid separator- I: Hydrodynamic performance, Fuel Processing Technology, 126 (2014) 366-382

[8] A. A. Lappas, M. C. Samolada, D. K. latridis, S. S. Voutetakis, I. A. Vasalos Biomass pyrolysis in a circulating fluid bed reactor for the production of fuels and chemicals, Fuel, 81 (2002) 2087-2095

[9] R. S., Miller, J. Bellan, A generalized biomass pyrolysis model based on superimposed cellulose, hemicellulose, and lignin kinetics. Combustion Science and Technology 126 (1997) 97-137.

[10] K. Papadikis, S. Gu, A.V. Bridgwater, H. Gerhauser, Application of CFD to model fast pyrolysis of biomass, Fuel Processing Technology, 90 (2009) 504-512

[11] W. R. Chan, M. Kelbon, B. B. Krieger, Modelling and experimental verification of physical and chemical processes during pyrolysis of large biomass particle, Fuel 64 (1985) 1505-1513

[12] A. G. Liden, F. Berruti, D. S. Scott, A kinetic model for the production of liquids from the flash pyrolysis of biomass, Chemical Engineering Communications 65 (1988) 207-221

[13] C. Di Blasi, Analysis of conversion and secondary reaction effect within porous solid fuels undergoing pyrolysis, Combustion Science Technology 90 (1993) 315-339

[14] K. Papadikis, H. Gerhauser, A. V. Bridgwater, S. Gu, CFD modelling of the fast pyrolysis of an in-flight cellulosic particle subjected to convective heat transfer, Biomass and Bioenergy, 33 (2009) 97-107

[15] F. J.Kilzer, A.Broido, Speculation on the nature of cellulose pyrolysis. Pyrodynamics, 2(1965) 151-163

[16] F. Shafizadeh, Pyrolytic reaction and products of biomass. Fundamentals of thermochemical biomass conversion. Ed. R. P. Overend, T. A. Milne and L. K. Mudge. Elsevier Science Pub. (1985) 183-217

[17] K. Papadikis, S. Gu, A.V. Bridgwater, CFD modelling of the fast pyrolysis of biomass in fluidised bed reactors: Modelling the impact of biomass shrinkage, Chemical Engineering Journal, 149 (2009) 417-427

[18] Q. Xue, T.J. Heindel, R. O. Fox, A CFD model for biomass fast pyrolysis in fluidized-bed reactors, Chemical Engineering Science 66 (2011) 2440-2452 
[19] A. G. W. Bradbury, Y. Sakai, F. Shafizadeh, A kinetic model for pyrolysis of cellulose. Journal of Applied Polymer Science, 23 (1979) 3271-3280.

[20] Q. Xue, D. Dalluge, T.J. Heindel, R.O. Fox, R.C. Brown, Experimental validation and CFD modeling study of biomass fast pyrolysis in fluidized-bed reactors, Fuel 97 (2012) 757-769

[21] Q. Xue, R, O. Fox, Computational modeling of biomass thermochemical conversion in fluidized beds: particle density variation and size distribution, Industrial and Engineering Chemistry Research, DOI:10.1021/ie503806p.

[22] A. A. Boateng, P.L. Mtui, CFD modeling of space-time evolution of fast pyrolysis products in a bench-scale fluidized-bed reactor, Applied Thermal Engineering, 33-34 (2012), 190-198

[23] R. W. Ashcraft, G. J. Heynderickx, G. B. Marin, Modeling fast biomass pyrolysis in a gas-solid vortex reactor, Chemical Engineering Journal, 207 (2012) 195-208

[24] Q. Xiong, S. Aramideh, S. C. Kong, Modeling effects of operating conditions on biomass fast pyrolysis in bubbling fluidized bed reactors, Energy fuels, 27 (2013) 5948-5956

[25] P. Mellin, Q. Zhang, E. Kantarelis, W. Yang, An Euler-Euler approach to modeling biomass fast pyrolysis in fluidized-bed reactors-focusing on the gas phase, Applied Thermal Engineering 58 (2013) 344-353

[26] P. Mellin , E. Kantarelis, W. Yang, Computational fluid dynamics modeling of biomass fast pyrolysis, in a fluidized bed reactor, using a comprehensive chemistry scheme, Fuel, 117 (2014) 704-715

[27] E. Ranzi, A. Cuoci, T. Faravelli, A. Frassoldati, G. Migliavacca, S. Pierucci, S. Sommariva, Chemical kinetics of biomass pyrolysis. Energy\&Fuel, 22 (2008) 42924300 .

[28] M. Calonaci, G. Grana, E. B. Hemings, G. Bozzano, M. Dente, E. Ranzi Comprehensive kinetic modeling study of bio-oil formation from fast pyrolysis of biomass. Energy Fuel 24(2010) 5727-5734.

[29] J. Blondeau, H. Jeanmart, Biomass pyrolysis at high temperatures: prediction of gaseous species yields from an anisotropic particle, Biomass Bioenergy 41(2012)107-121

[30] M. Huard, F. Berruti and C. Briens, Experimental Study of a Novel Fast GasSolid Separator for Pyrolysis Reactors, International Journal of Chemical Reactor Engineering, 8 (2010)

[31] X. T. Li, J. R. Grace, C. J. Lim, A. P. Watkinson, H. P. Chen, J. R. Kim, Biomass gasification in a circulating fluidized bed, Biomass and Bioenergy, 26 (2004) 171-193

[32] X. T. Li, J. R. Grace, A. P. Watkinson, C. J. Lim, A. E. Ergudenler, Equlibrium modeling of gasification: a free energy minimization approach and its application to a circulating fluidized bed coal gasifier, Fuel, 80 (2001) 195-207 
[33] S. A. Channiwala, P. P. Parikh, A unified correlation for estimating HHV of solid, liquid and gaseous fuels, Fuel, 81 (2002) 1051-1063

[34] D. Radlein, J. Piskorz, D. S. Scott, Fast pyrolysis of natural polysaccharides as a potential industrial process, Journal of Analytical and Applied Pyrolysis, 19(1991) 4163

[35] M. Syamlal, L. Bisset, METC Gasifier Advanced Simulation (MGAS) Model, U.S. Department of Energy Office of Fossil Energy, Morgantown Energy Technology Center P.O. Box 880, Morgantown, West Virginia 26507-0880, (1991).

[36] F. V. Tinaut, A. Melgar, J. F. Pérez, A. Horrillo, Effect of biomass particle size and air superficial velocity on the gasification process in a downdraft fixed bed gasifier. An experimental and modelling study, Fuel Processing Technology, 89 (2008) 1076-1089.

[37] W. Lee, A Pressure Iteration Scheme for Two-Phase Flow Modeling, Los Alamos Scientific Laboratory, Los Alamos, New Mexico (1979)

[38] C. Di Blasi, Modelling Wood Gasification in a Counter current Fixed-Bed Reactor, AIChE Journal, 50(2004) 2306-2319.

[39] S. Gerber, F. Behrendt, M. Oevermann, An Eulerian modeling approach of wood gasification in a bubbling fluidized bed reactor using char as bed material, Fuel, 89((2010) 2903-2917.

[40] C. Branca, C., Di Blasi, Kinetics of the isothermal degradation of wood in the temperature range 528-708 K. Journal of Analytical and Applied Pyrolysis 67 (2003) 207-219

[41] F. Bérangère, P. Laurent, P. Agnès, D. Claude-Gilles, Chapter: Methodology for Bioprocess Analysis: Mass Balances, Yields and Stoichiometrie in Book, A. Innocenti, Stoichiometry and research- the importance of quantity in Biomedicine. 2012, InTech.

[42] Y. Wu, W. Yang, W. Blasiak, Energy and exergy analysis of high temperature agent gasification of biomass, Energies, 7 (2014) 2107-2122

[43] V. Pasangulapati, Develatilization characteristics of cellulose, hemicellulose, lignin and the selected biomass during thermochemical gasification: experiment and modelling studies, Master of science thesis, 2012

[44] S. A. Vasquez and V. A. Ivanov, A Phase Coupled Method for Solving Multiphase Problems on Unstructured Meshes, ASME 2000 Fluids Engineering Division Summer Meeting, (2000)

[45] P. C. Johnson and R. Jackson, Frictional-Collisional Constitutive Relations for Granular Materials, with Application to Plane Shearing, Journal of Fluid Mechanics, 176 (1987) 67-93 
[46] J. Aubin, L. Prat, C. Xuereb, C. Gourdon, Effect of microchannel aspect ratio on residence time distributions and the axial dispersion coefficient, Chemical Engineering and Processing: Process Intensification, 48 (2009) 554-559.

[47] T. Ding, S. Li, J. Xie, W. Song, J. Yao, W. Lin, Rapid Pyrolysis of wheat straw in a bench-scale circulating fluidized-bed downer reactor, Chemical Engineering Technology, 35 (2012) 2170-2176.

[48] N. Punsuwan and C. Tangsathitkulchai, Product characterization and kinetics of biomass pyrolysis in a three-zone free-fall reactor, International Journal of Chemical Engineering, Article ID 986719 (2014), 10 pages.

[49] A. V. Bridgwater, Review of fast pyrolysis of biomass and product upgrading, Biomass and Bioenergy, 83 (2012) 68-94

[50] R. J. M. Westerhof, N. J. M. Kuipers, S. R. A. Kersten, and W. P. M. van Swaaij, Controlling the Water Content of Biomass Fast Pyrolysis Oil, Industrial \& Engineering Chemistry Research 46 (2007) 9238-9247

[51] K. Raveendran, A. Ganesh, Heating value of biomass and biomass pyrolysis products, Fuel, 75 (1996) 1715-1720.

[52] A. Demirbas, Determination of calorific values of bio-chars and pyro-oils from pyrolysis of beech trunkbarks, Journal of Analytical and Applied Pyrolysis, 72 (2004) 215-219

[53] T. Imam, S. Capareda, Characterization of bio-oil, syn-gas and bio-char from switchgrass pyrolysis at various temperatures, Journal of Analytical and Applied Pyrolysis, 93 (2012) 170-177. 
Table 1. Summary of recent literatures on CFD modelling of biomass pyrolysis

\begin{tabular}{|c|c|c|c|}
\hline Author (Ref.) & Reactor & Material; heating conditions & CFD model; reaction kinetics \\
\hline $\begin{array}{l}\text { Papadikis et al } \\
{[10]}\end{array}$ & $\begin{array}{l}\text { Fluidized bed, } 1.2 \mathrm{~m} / \mathrm{s} \\
\text { nitrogen }\end{array}$ & $\begin{array}{l}\text { Single cellulosic particle } \\
\qquad(500 \mu \mathrm{m}) ; 773 \mathrm{~K}\end{array}$ & $\begin{array}{c}\text { Eulerian-Lagrangian; Two stage, semi global } \\
\text { model : primary pyrolysis[11], second pyrolysis } \\
{[12,13]}\end{array}$ \\
\hline $\begin{array}{l}\text { Papadikis et al } \\
{[14]}\end{array}$ & $\begin{array}{l}\text { Fluidized bed, } 1.2 \mathrm{~m} / \mathrm{s} \\
\text { nitrogen }\end{array}$ & $\begin{array}{c}\text { Singe cellulosic particle } \\
(500 \mu \mathrm{m}) ; 773 \mathrm{~K}\end{array}$ & $\begin{array}{c}\text { Eulerian-Lagrangian; Broido-Shafizadeh } \\
\text { mechanism based on cellulose }[15,16]\end{array}$ \\
\hline $\begin{array}{l}\text { Papadikis et al } \\
{[17]}\end{array}$ & $\begin{array}{l}\text { Fluidized bed, } 0.3 \mathrm{~m} / \mathrm{s} \\
\text { nitrogen }\end{array}$ & $\begin{array}{l}\text { Single cellulosic particle } \\
\quad(500 \mu \mathrm{m}) ; 773 \mathrm{~K}\end{array}$ & $\begin{array}{c}\text { Eulerian-Lagrangian; Two stage, semi global } \\
\text { model : primary pyrolysis[11], second pyrolysis } \\
{[12,13]}\end{array}$ \\
\hline Xue et al. [18] & $\begin{array}{l}\text { 2D Fluidized bed, } 0.42 \\
\mathrm{~m} / \mathrm{s} \text { nitrogen }\end{array}$ & $\begin{array}{l}\text { Pure cellulose and bagasse } \\
(500 \mu \mathrm{m}) ; 790 \mathrm{~K}\end{array}$ & $\begin{array}{c}\text { Eulerian-Eulerian; Multi-component, multi- } \\
\text { stage model }[9,19]\end{array}$ \\
\hline Xue et al [20] & $\begin{array}{l}\text { 2D and 3D Fluidized bed, } \\
1.5 \sim 3 \cup_{\mathrm{mf}} \text { nitrogen }\end{array}$ & $\begin{array}{l}\text { Pure cellulose, bagasse, corn } \\
\text { stover, switchgrass and red } \\
\text { oak }(500 \mu \mathrm{m}) ; 773 \mathrm{~K}\end{array}$ & $\begin{array}{l}\text { Eulerian-Eulerian; Multi-component, multi- } \\
\text { stage model }[9,19]\end{array}$ \\
\hline $\begin{array}{l}\text { Boateng and } \\
\text { Mtui [22] }\end{array}$ & $\begin{array}{l}\text { Fluidized bed, } 0.23 \mathrm{~m} / \mathrm{s} \\
\text { nitrogen }\end{array}$ & $\begin{array}{c}\text { Switchgrass, corn stover } \\
\text { and soybean straw }(500 \mu \mathrm{m}) \\
753-823 \mathrm{~K}\end{array}$ & $\begin{array}{l}\text { Eulerian-Eulerian; One global step pyrolysis } \\
\text { model based on elemental analysis }\end{array}$ \\
\hline $\begin{array}{l}\text { Ashcraft et al } \\
\text { [23] }\end{array}$ & $\begin{array}{c}\text { Gas-solid vortex reactor, } \\
0.222 \sim 0.444 \mathrm{~kg} / \mathrm{s} \\
\text { nitrogen }\end{array}$ & $\begin{array}{c}36 \% \text { cellulose, } 47 \% \\
\text { hemicellulose and } 17 \% \text { lignin } \\
\text { (dry basis) or } 10 \% \text { additional } \\
\text { water }(500 \mu \mathrm{m}) ; 773 \mathrm{~K}\end{array}$ & $\begin{array}{c}\text { Eulerian-Eulerian; Multi-component, multi- } \\
\text { stage model }[9,19]\end{array}$ \\
\hline Xiong et al [24] & $\begin{array}{l}\text { 2D and } 3 D \text { fluidized bed, } \\
4.81 \mathrm{~kg} / \mathrm{h} \text { nitrogen }\end{array}$ & $\begin{array}{c}42 \% \text { cellulose, } 34 \% \\
\text { hemicellulose and } 24 \% \text { lignin } \\
(500 \mu \mathrm{m}) ; 773 \mathrm{~K}\end{array}$ & $\begin{array}{l}\text { Eulerian-Eulerian; Shafizadeh-Chin } \\
\text { decomposition model [9] }\end{array}$ \\
\hline Mellin et al [25] & $\begin{array}{l}\text { Bubbling fluidized bed, } \\
0.15-0.4 \mathrm{~m} / \mathrm{s} \text { nitrogen }\end{array}$ & $\begin{array}{c}92.4 \% \text { volatiles, } 0.6 \% \text { ash and } \\
7 \% \text { moisture }(700-1000 \mu \mathrm{m}) \\
773 \mathrm{~K}\end{array}$ & Eulerian-Eulerian; Primary pyrolysis [19] \\
\hline Mellin et al [26] & $\begin{array}{l}\text { Bubbling fluidized } \\
\text { bed, } 0.00045 \mathrm{~kg} / \mathrm{s} \\
\text { nitrogen }\end{array}$ & $\begin{array}{c}\text { Biomass }\left(\mathrm{C}_{6} \mathrm{H}_{8.46} \mathrm{O}_{3.9}\right)(850 \\
\mu \mathrm{m}) ; 736 \mathrm{~K}\end{array}$ & $\begin{array}{c}\text { Eulerian-Eulerian; Multi-component, multi- } \\
\text { stage model: primary pyrolysis [27, 28], second } \\
\text { pyrolysis [29], and tar cracking. }\end{array}$ \\
\hline
\end{tabular}


Table 2. Simulation parameters

\begin{tabular}{lclc}
\hline \multicolumn{1}{c}{ Parameters } & Value & \multicolumn{1}{c}{ Parameters } & Value \\
\hline Pressure outlet $[\mathrm{pa}]$ & 101,325 & Reactor height $[\mathrm{m}]^{*}$ & 1.335 \\
Biomass flow rate $[\mathrm{g} / \mathrm{s}]$ & 5 & Reactor diameter $[\mathrm{m}]^{*}$ & 0.069 \\
Sand flow rate $[\mathrm{g} / \mathrm{s}]$ & 80 & separator angle [degree] & 60 \\
Sand size $[\mu \mathrm{m}]$ & 200 & Separator to pipe distance $[\mathrm{m}]^{*}$ & 0 \\
Sand density $\left[\mathrm{kg} \mathrm{m}{ }^{-3}\right]$ & 2650 & Biomass inlet temperature $[\mathrm{K}]$ & 298 \\
Biomass size $[\mu \mathrm{m}]$ & 200 & Sand inlet temperature $[\mathrm{K}]$ & 973 \\
$\mathrm{~N}_{2}$ inlet velocity $[\mathrm{m} / \mathrm{s}]$ & 0.05 & $\mathrm{~N}_{2}$ inlet temperature $[\mathrm{K}]$ & 298 \\
\hline
\end{tabular}

${ }^{*}$ Further details on the reactor and separator geometry can be found in Yu et al. [7]

Table 3. Chemical composition of switch grass [22]

\begin{tabular}{ccccc}
\hline & Fixed carbon & Moisture & Volatile & Ash \\
Proximate analysis (wt\%) & 13.81 & 2.65 & 81.20 & 2.54 \\
\hline & $\mathrm{C}$ & $\mathrm{H}$ & $\mathrm{O}$ & $\mathrm{N}$ \\
Ultimate analysis (wt\%) & 48.8 & 6.99 & 43.68 & 0.53 \\
\hline
\end{tabular}

Table 4. Stoichiometric coefficient used in the pyrolysis reaction (Eq. 21) [22]

\begin{tabular}{ccccccc}
\hline$\alpha_{1}$ & $\alpha_{2}$ & $\alpha_{3}$ & $\alpha_{4}$ & $\alpha_{5}$ & $\alpha_{6}$ & $\alpha_{7}$ \\
\hline 0.138 & 0.805 & 0.15 & 0.003 & 0.035 & 0.018 & 0.008 \\
\hline
\end{tabular}




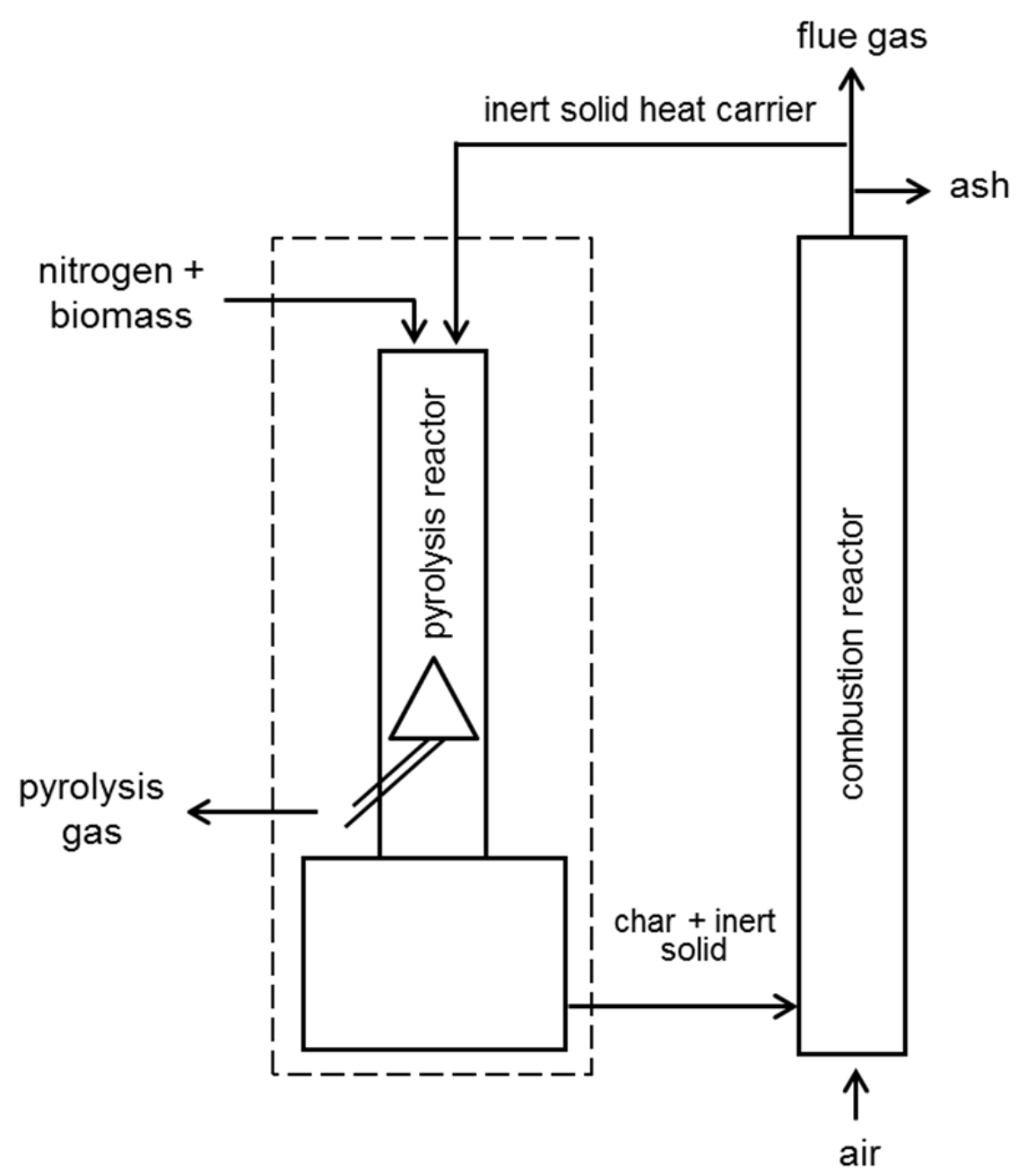

Fig. 1. Proposed concept of biomass pyrolysis in a downer reactor integrated with a combustor in a dual fluidized bed arrangement. The dashed line indicates the boundary of the simulation domain. 


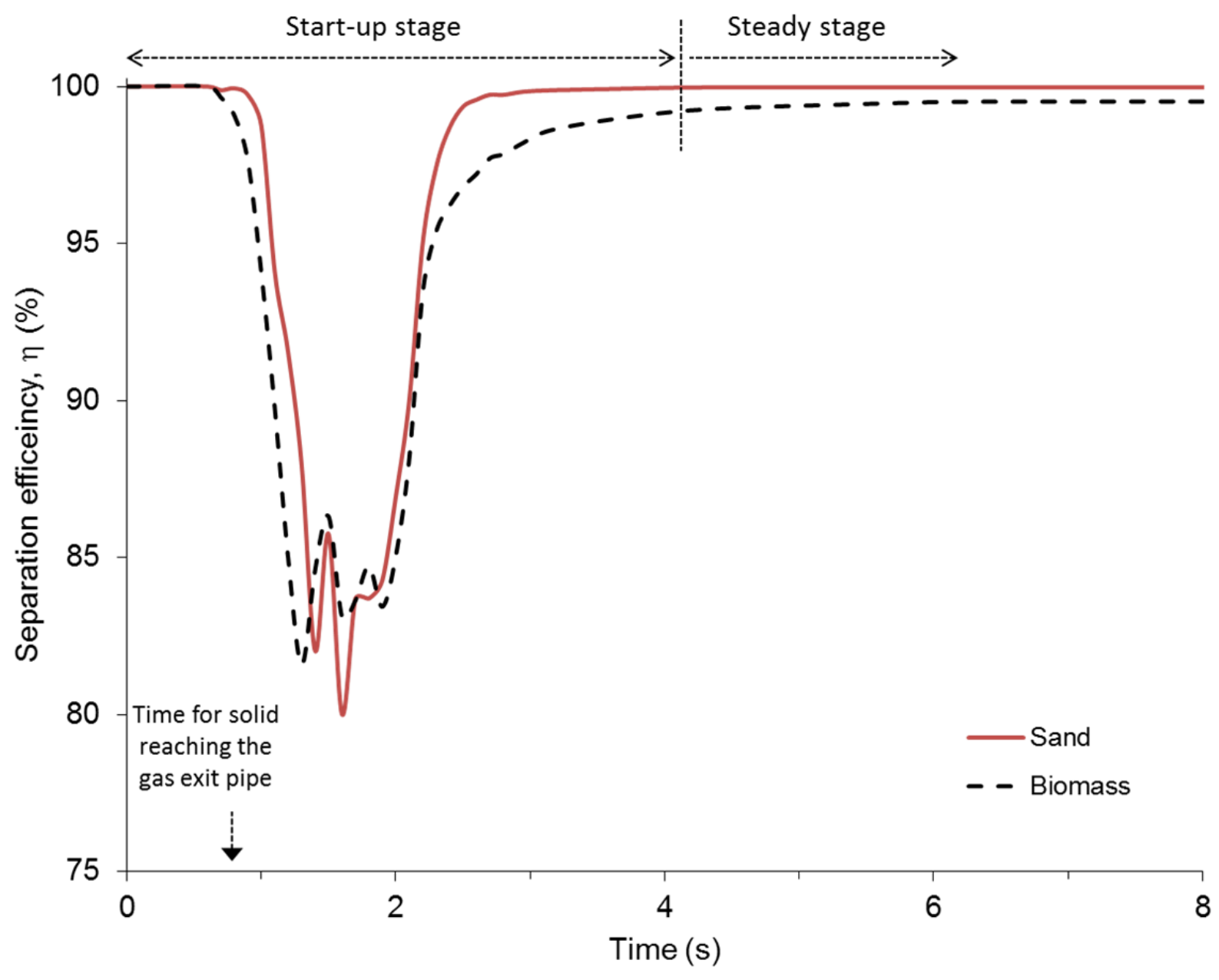

Fig. 2. Temporal evolution of the solid-gas separation efficiency. 


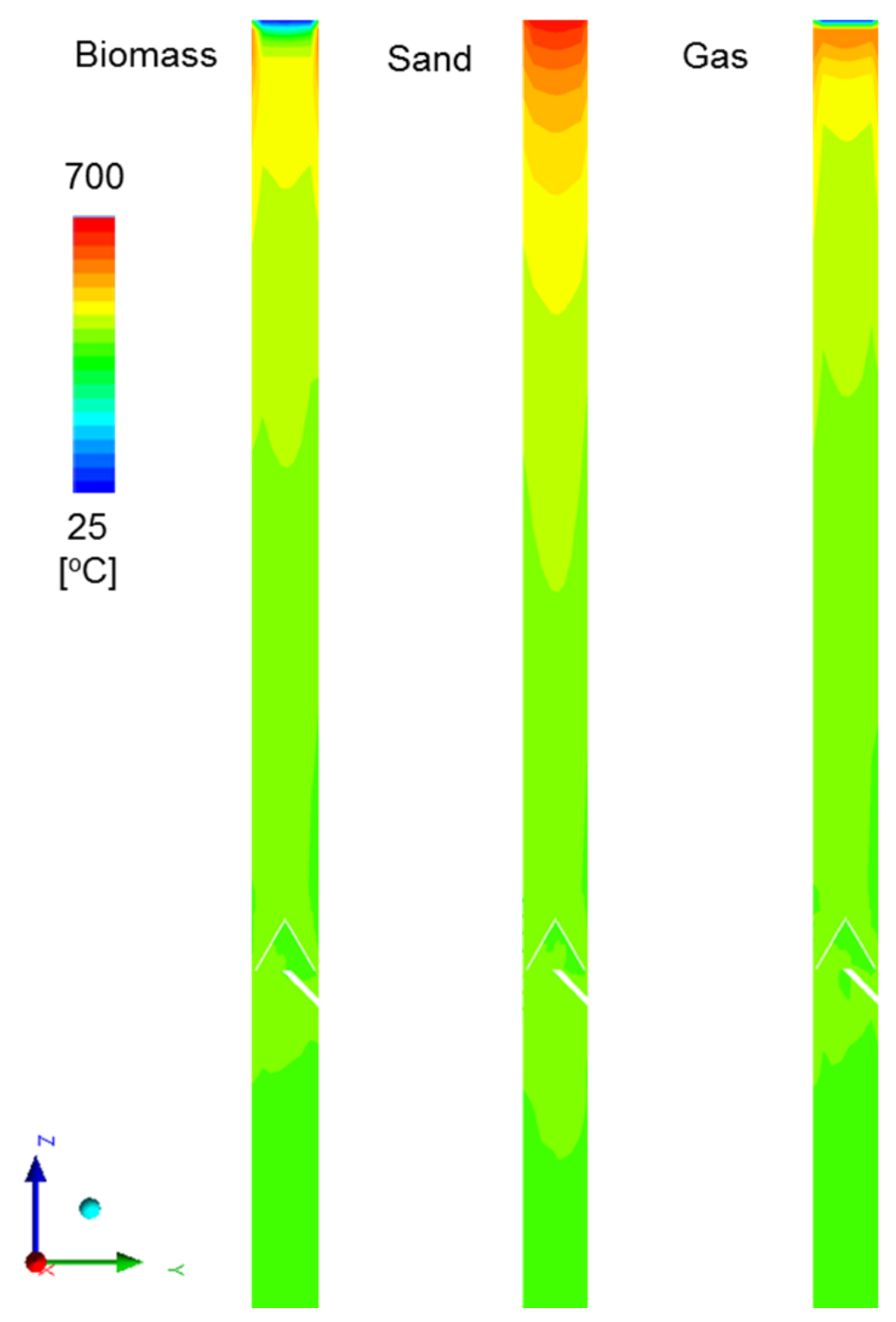

Fig. 3. Contour of the temperature distribution for the pyrolysis gas, biomass and sand phases in the downer reactor at steady state condition. 


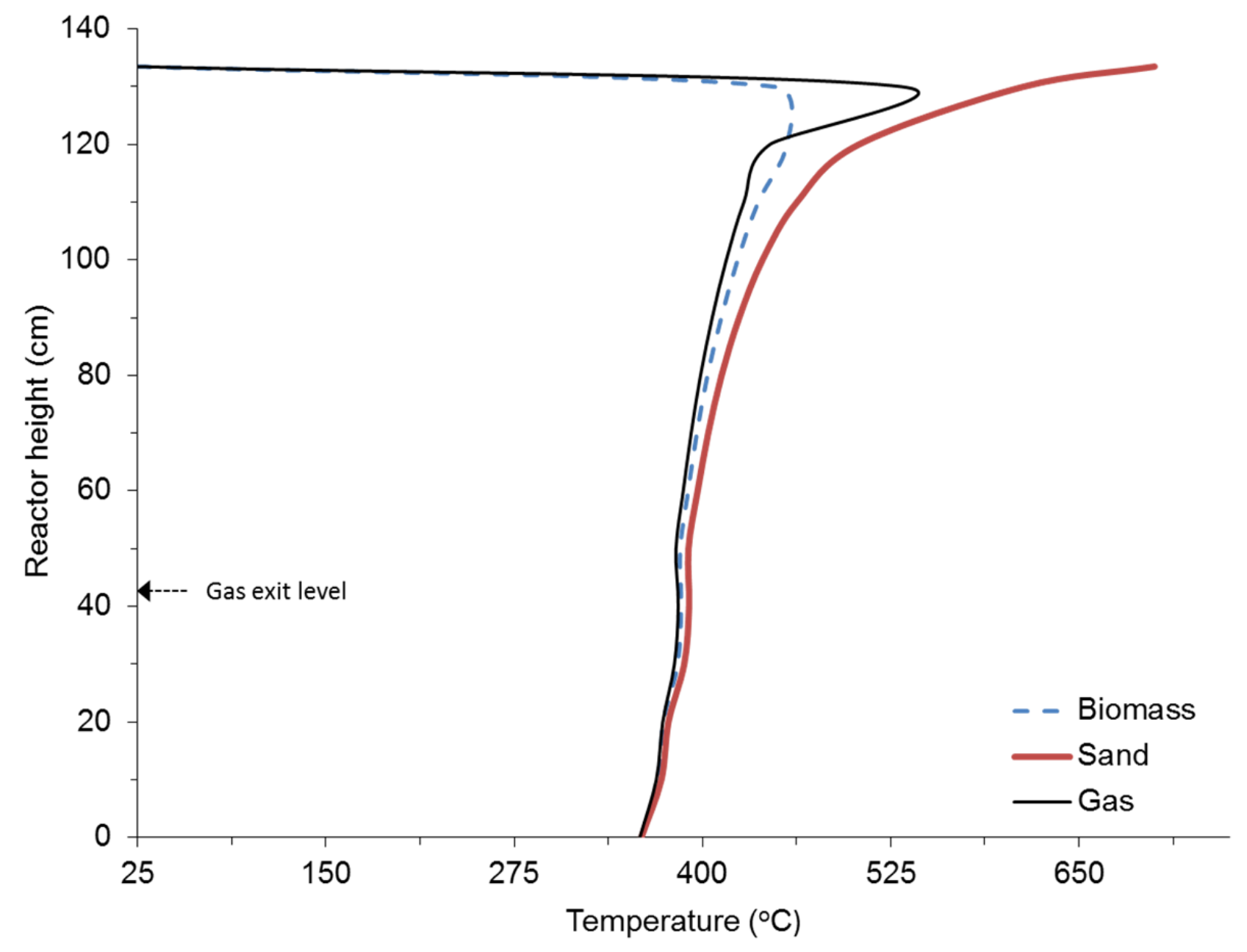

Fig. 4. Temperature of the pyrolysis gas, biomass and sand phases along the reactor height at steady state condition. The top of the reactor is at $133.5 \mathrm{~cm}$. 


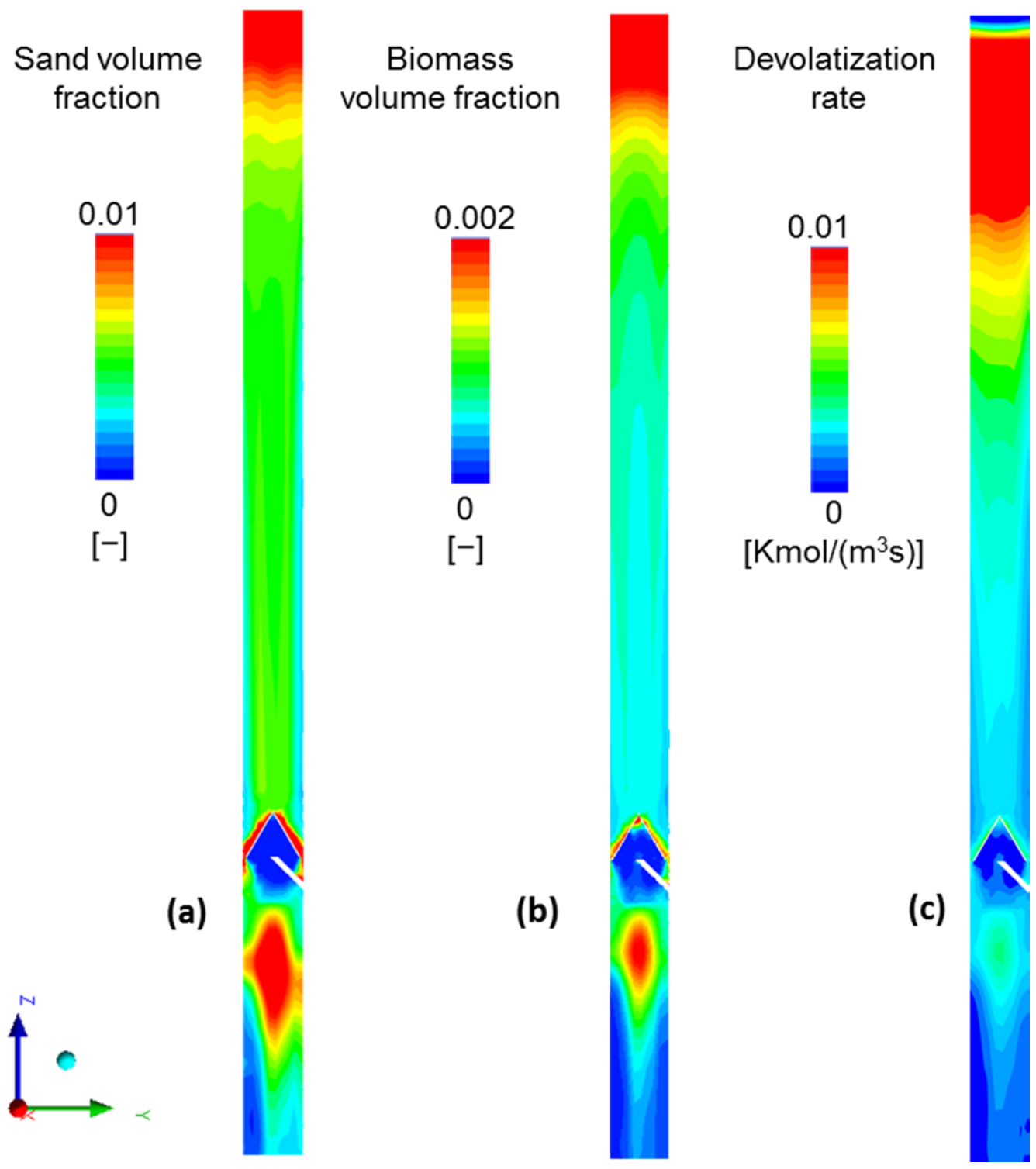

Fig. 5. Contours of the (a) sand concentration (b) biomass concentration and (c) devolatilization rate at steady state condition after $5 \mathrm{~s}$ operation. The colour ranges are restricting for better visualization. The maximum values are 0.133 and 0.022 for sand and biomass concentrations respectively and $0.041 \mathrm{kmol} \mathrm{m}^{-3} \mathrm{~s}^{-1}$ for the devolatilization. 


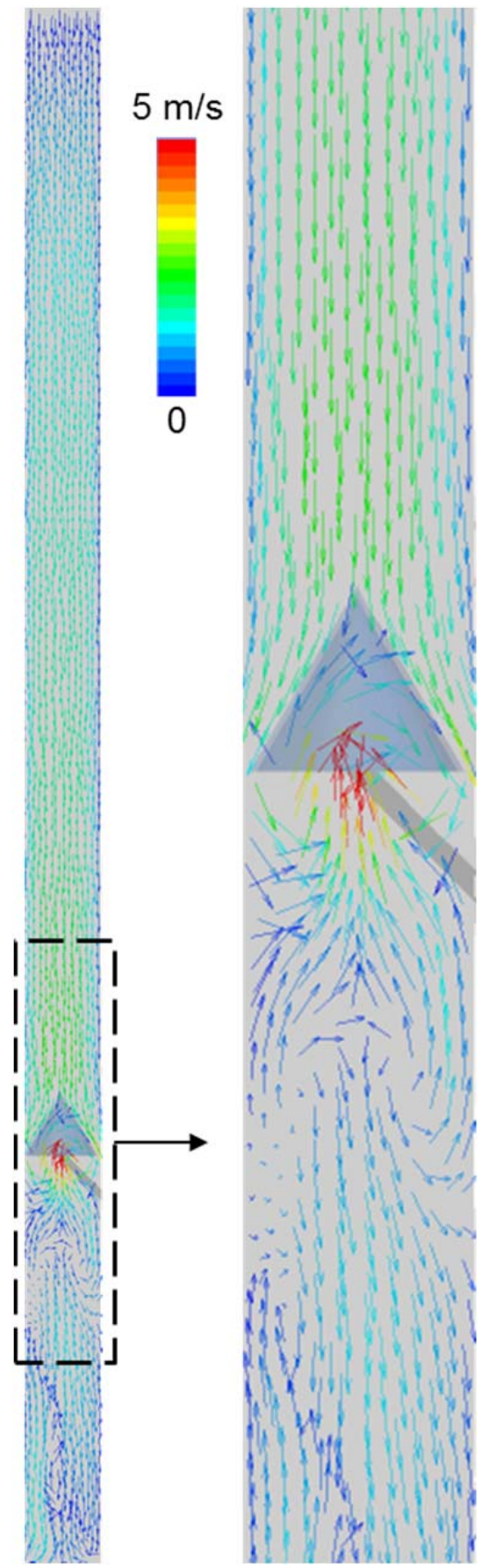

Fig. 6. The gas velocity vectors along the pyrolysis reactor with zoom-in at the solid-gas separator zone at steady state condition. 


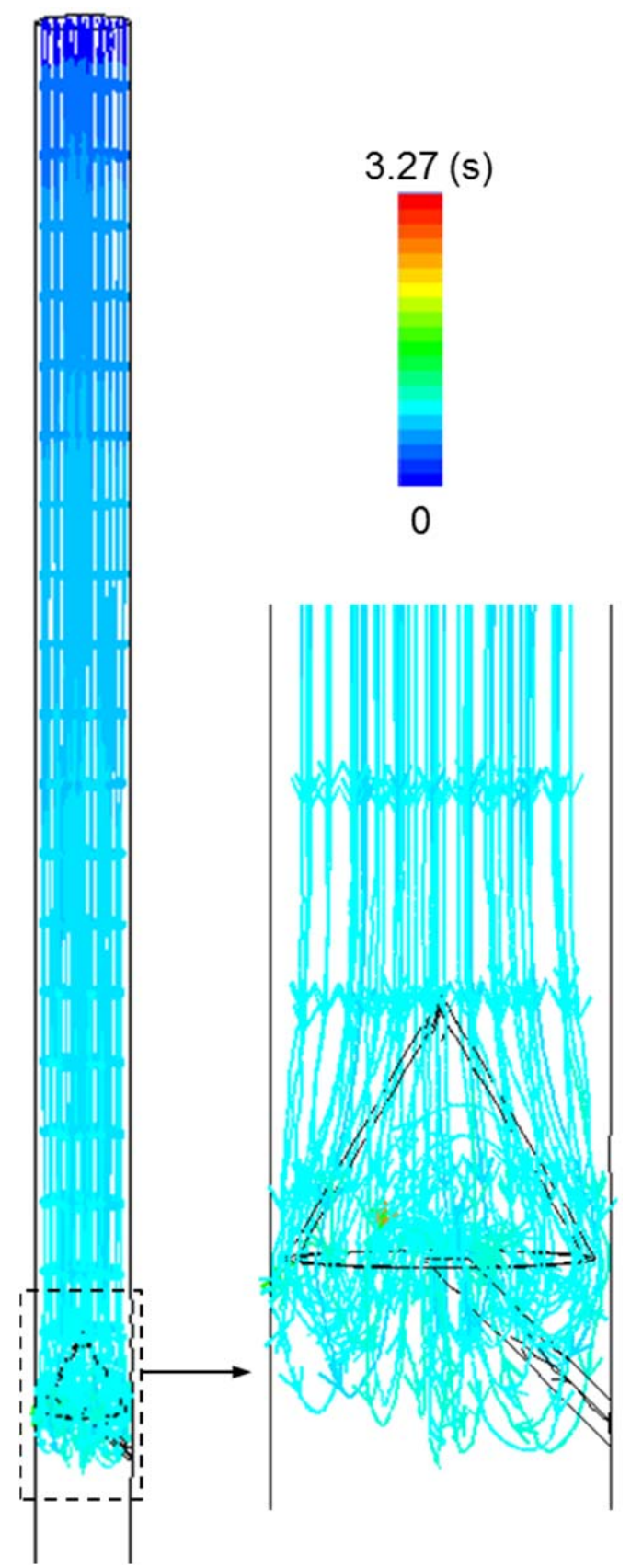

Fig. 7. Path lines along the velocity field of gas at steady state condition. The colour code indicates the gas residence time at steady state condition. 


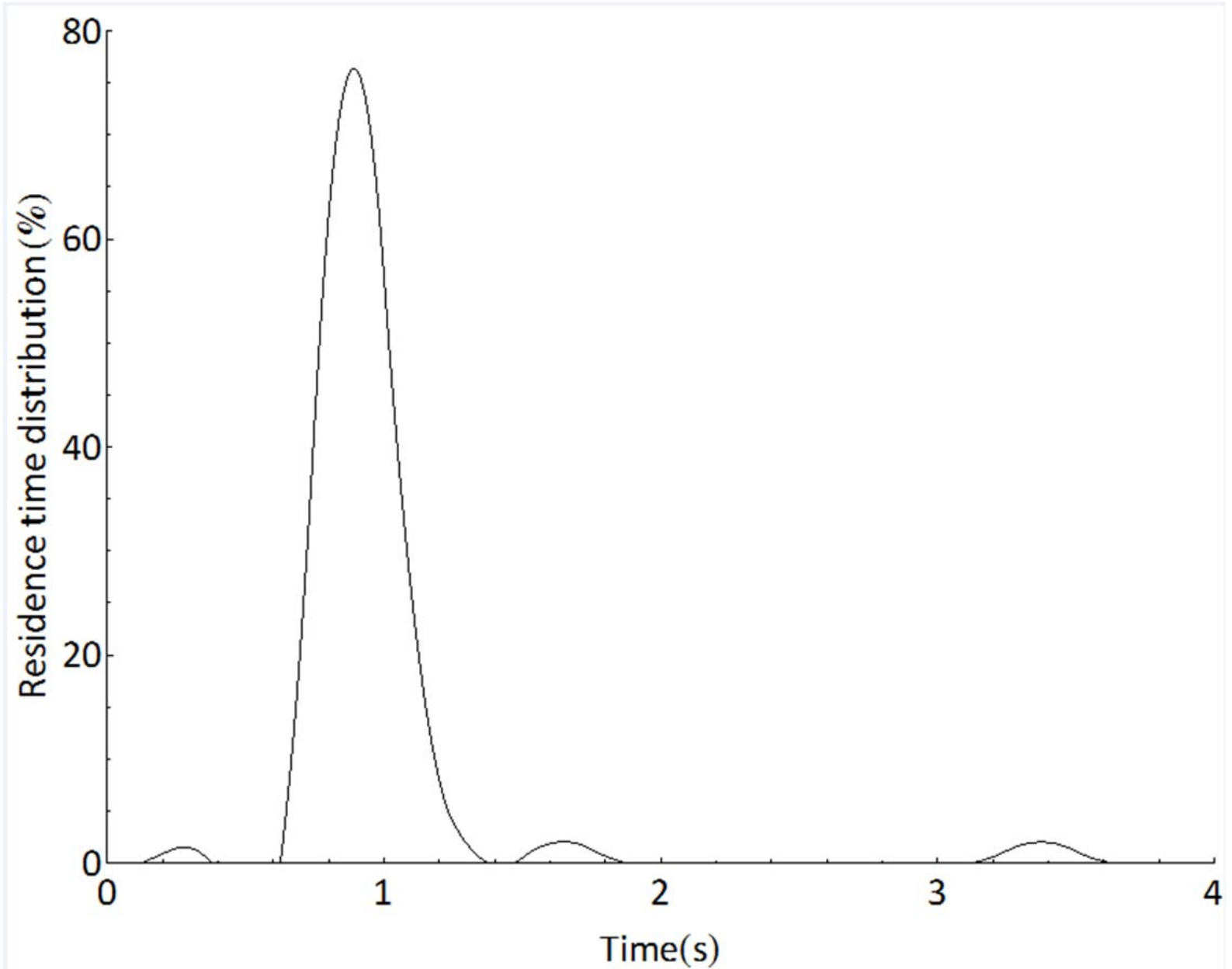

Fig. 8. The fitted gas residence time distribution based on path lines analysis. 


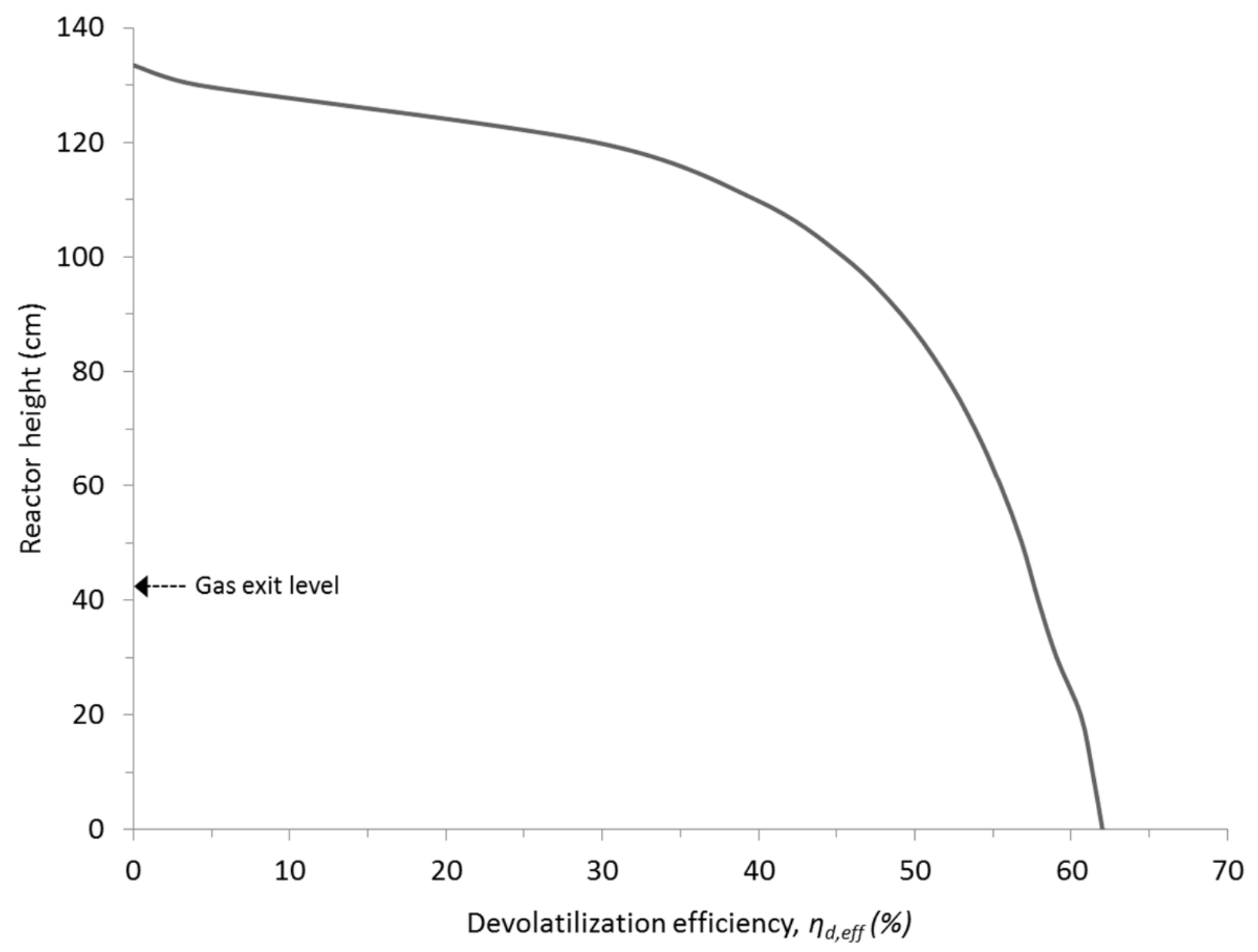

Fig. 9. Evolution of the devolatilization efficiency along the downer reactor height. 


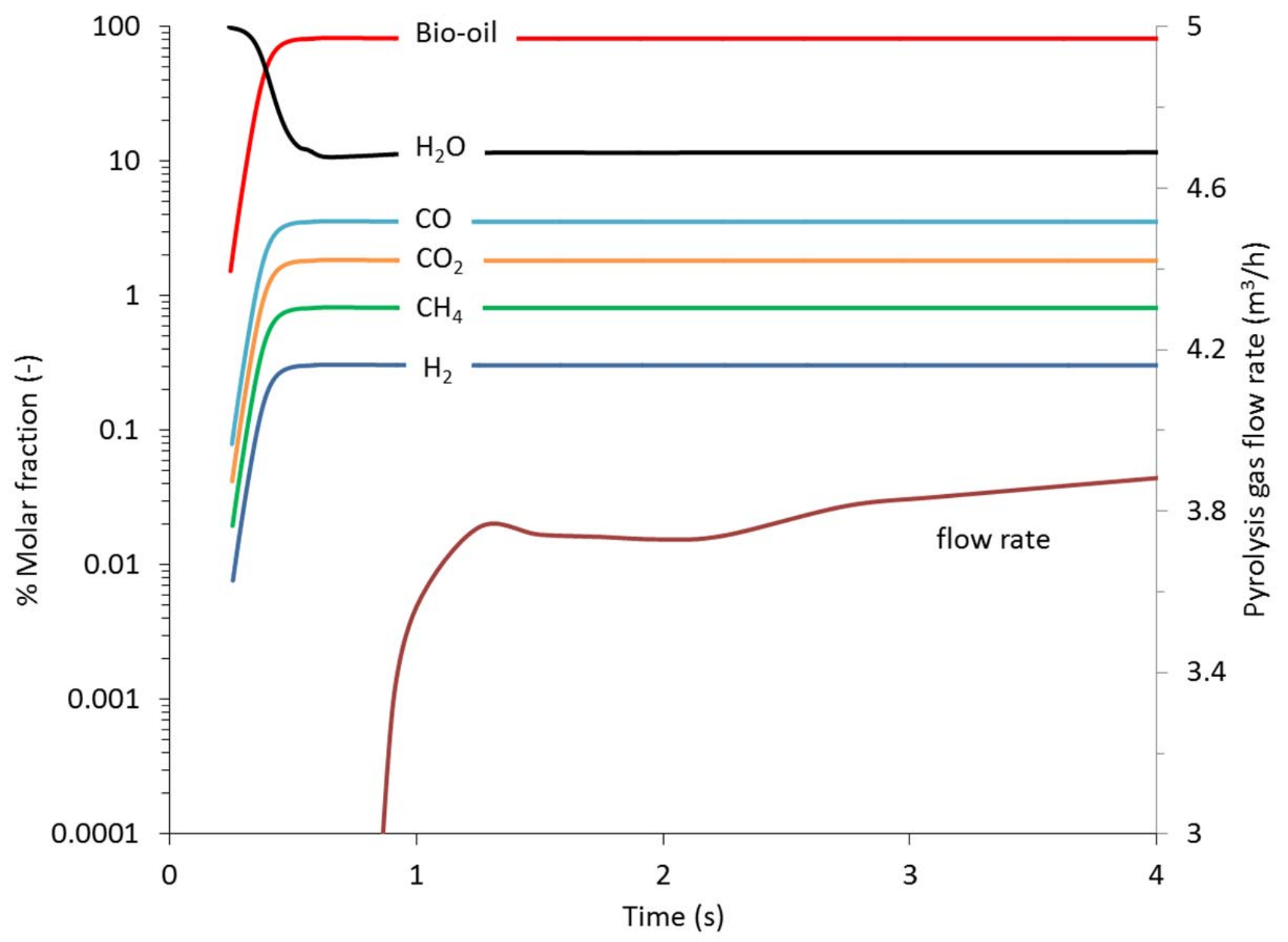

Fig. 10. Temporal evolution of the pyrolysis gaseous products (including condensable and non- condensable gas). 


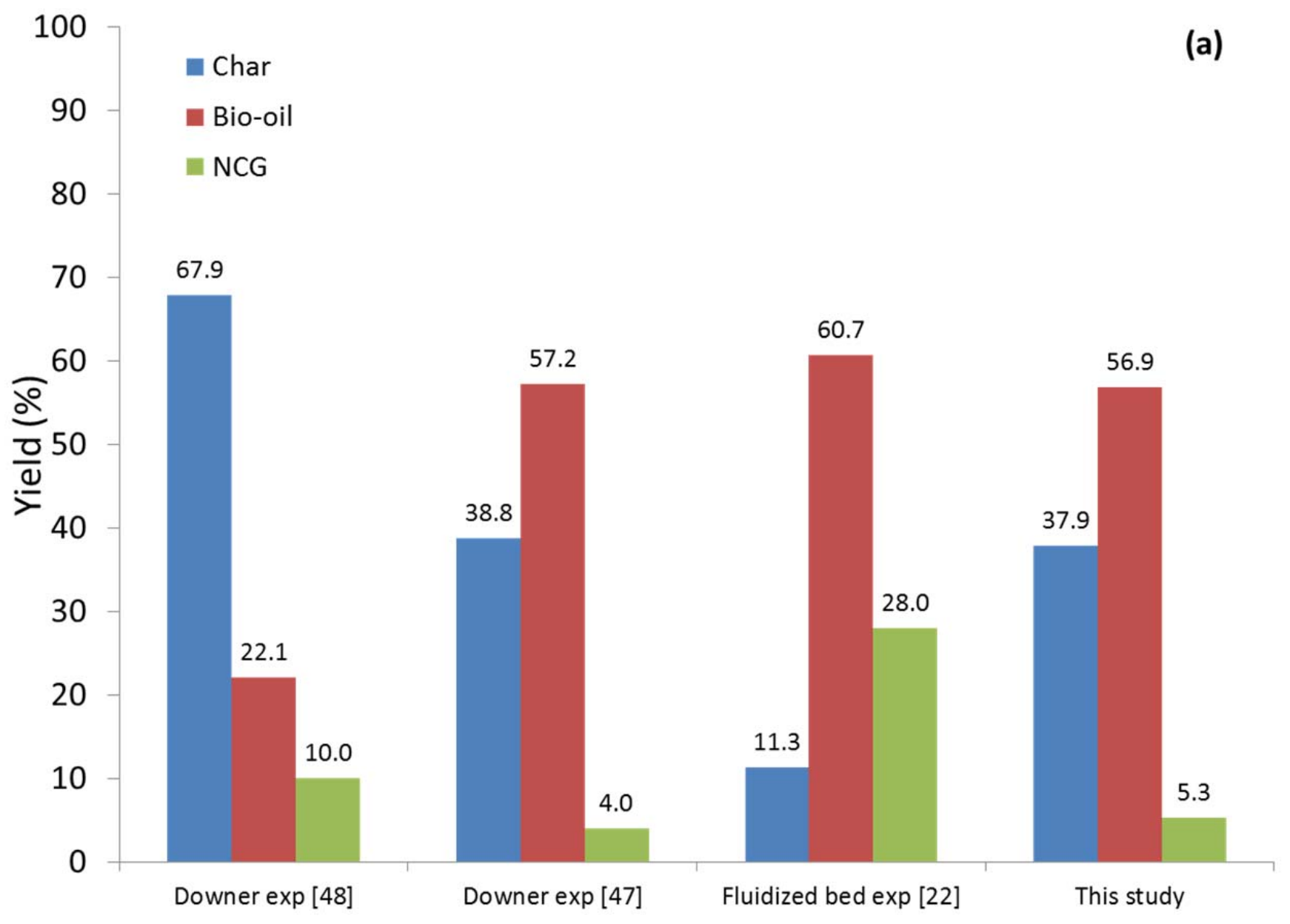




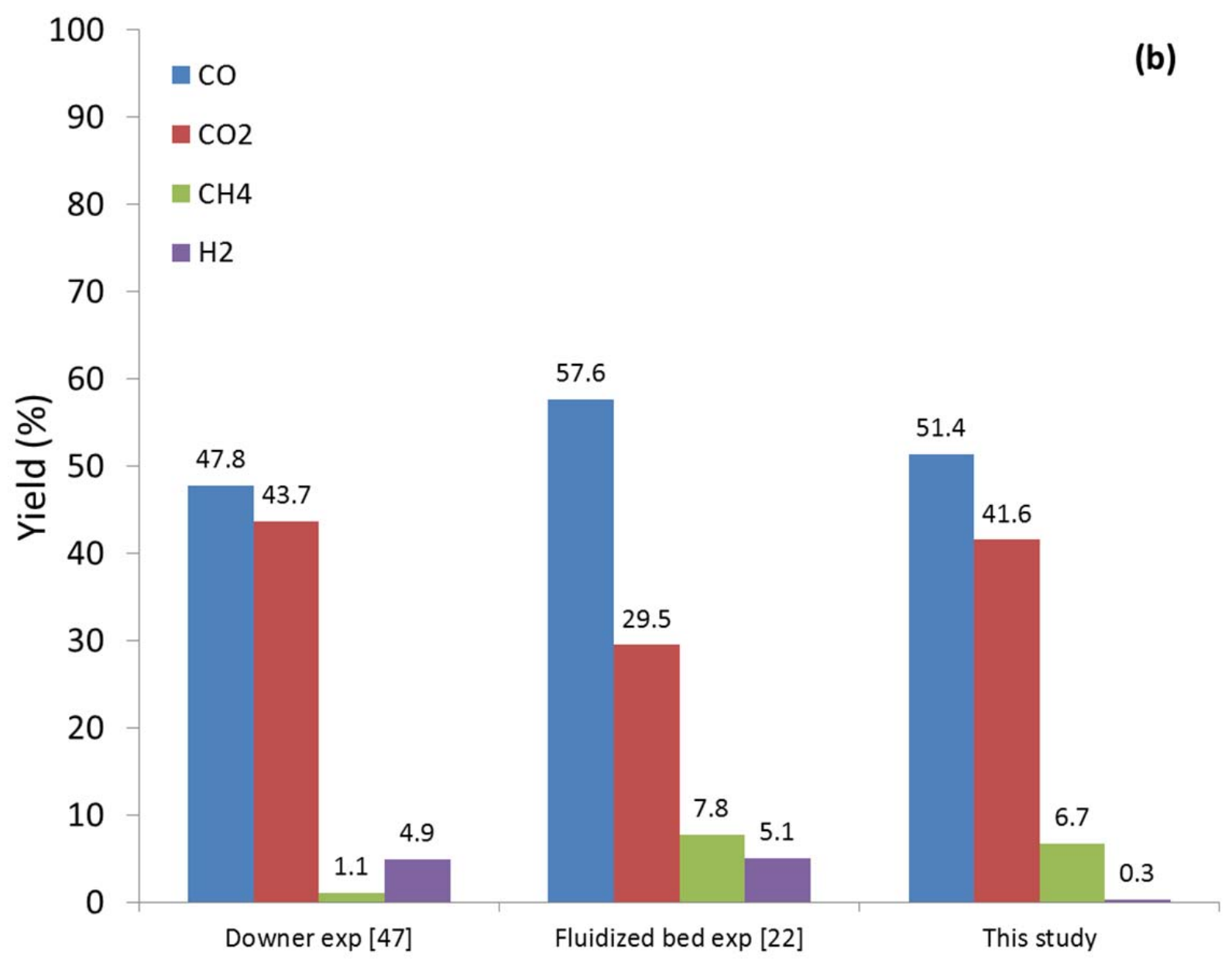

Fig. 11. Comparison of the predictions and experimental data from the literature for the mass fraction of the pyrolysis products at steady state condition (a) Overall products (b) non- condensable gases. See further details on the operating conditions in the comments table.

\begin{tabular}{|c|c|}
\hline Comments & $\begin{array}{l}\text { (1) Reactor [48]: } 0.1 \mathrm{~m} \text { diameter and } 1.1 \mathrm{~m} \text { height; biomass: Palm shell } \\
\text { of } 280 \mu \mathrm{m} \text { diameter; pyrolysis temperature of } 520^{\circ} \mathrm{C} \text {; heated section of } \\
0.2 \mathrm{~m} \text {. } \\
\text { (2) Reactor [47]: } 0.039 \mathrm{~m} \text { diameter and } 3 \mathrm{~m} \text { height; biomass: acid treated } \\
\text { wheat straw of } 180 \sim 280 \mu \mathrm{m} \text { diameter; pyrolysis temperature of } 400{ }^{\circ} \mathrm{C} \text {. } \\
\text { (3) Reactor [22]: } 0.075 \mathrm{~m} \text { diameter and } 0.5 \mathrm{~m} \text { height; material: Switch } \\
\text { grass of } 500 \mu \mathrm{m} \text { size; wall temperature } 480-550{ }^{\circ} \mathrm{C} \text {. }\end{array}$ \\
\hline
\end{tabular}

